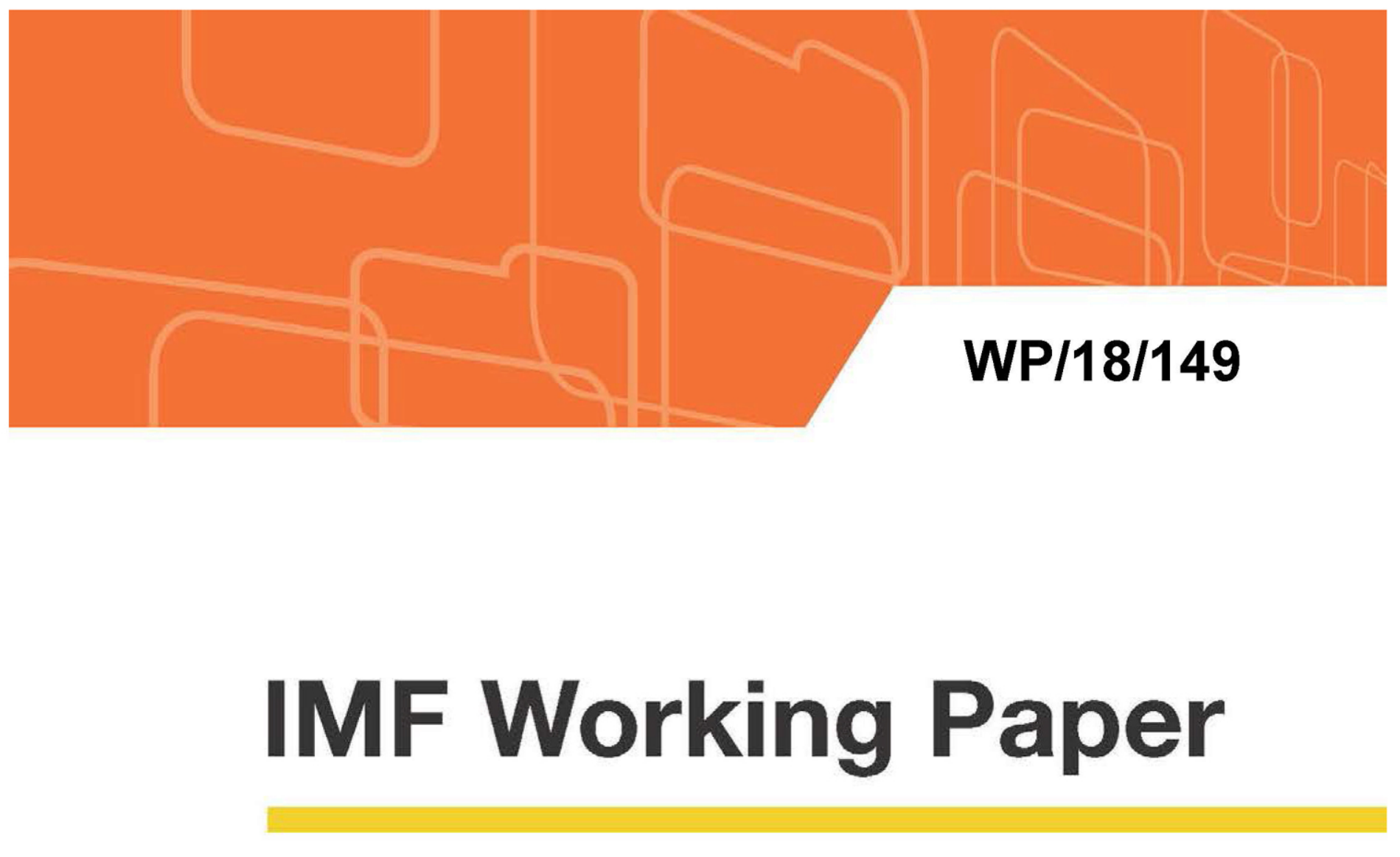

\title{
An Open Economy Quarterly Projection Model for Sri Lanka
}

by Chandranath Amarasekara, Rahul Anand, Kithsiri Ehelepola, Hemantha Ekanayake, Vishuddhi Jayawickrema, Sujeetha Jegajeevan,

Csaba Kober, Tharindi Nugawela, Sergey Plotnikov, Adam Remo, Poongothai Venuganan, and Rasika Yatigammana.

IMF Working Papers describe research in progress by the author(s) and are published to elicit comments and to encourage debate. The views expressed in IMF Working Papers are those of the author(s) and do not necessarily represent the views of the IMF, its Executive Board, or IMF management. 


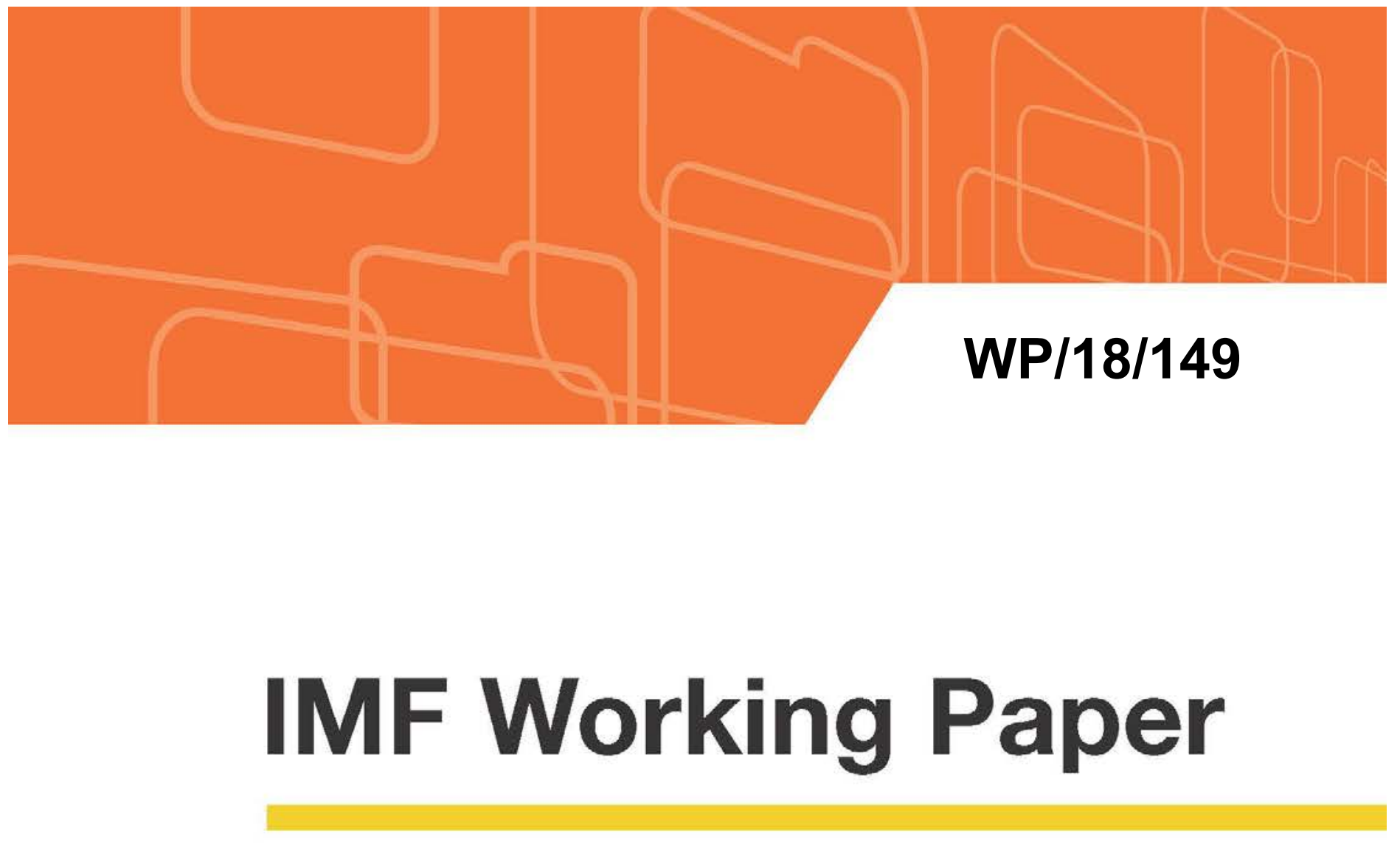

\section{An Open Economy Quarterly Projection Model for Sri Lanka}

by Chandranath Amarasekara, Rahul Anand, Kithsiri Ehelepola, Hemantha Ekanayake, Vishuddhi Jayawickrema, Sujeetha Jegajeevan, Csaba Kober, Tharindi Nugawela, Sergey Plotnikov, Adam Remo, Poongothai Venuganan, and Rasika Yatigammana.

IMF Working Papers describe research in progress by the author(s) and are published to elicit comments and to encourage debate. The views expressed in IMF Working Papers are those of the author(s) and do not necessarily represent the views of the IMF, its Executive Board, or IMF management.

\section{N T E R N A T I O N A L M O N E T A R Y F U N D}




\title{
IMF Working Paper
}

Institute for Capacity Development

\section{An Open Economy Quarterly Projection Model for Sri Lanka}

\section{Prepared by Chandranath Amarasekara, Rahul Anand, Kithsiri Ehelepola, Hemantha Ekanayake, Vishuddhi Jayawickrema, Sujeetha Jegajeevan, Csaba Kober, Tharindi Nugawela, Sergey Plotnikov, Adam Remo, Poongothai Venuganan, and Rasika Yatigammana}

\author{
Authorized for distribution by Andrew Berg
}

June 2018

IMF Working Papers describe research in progress by the author(s) and are published to elicit comments and to encourage debate. The views expressed in IMF Working Papers are those of the author(s) and do not necessarily represent the views of the IMF, its Executive Board, or IMF management.

\begin{abstract}
This study documents a semi-structural model developed for Sri Lanka. This model, extended with a fiscal sector block, is expected to serve as a core forecasting model in the process of the Central Bank of Sri Lanka's move towards flexible inflation targeting. The model includes a forward-looking endogenous interest rate and foreign exchange rate policy rules allowing for flexible change in policy behavior. It is a gap model that allows for simultaneous identification of business cycle position and long-term equilibrium. The model was first calibrated and then its data-fit was improved using Bayesian estimation technique with relatively tight priors.
\end{abstract}

JEL Classification Numbers: C15; C50; E17; E47; E52

Keywords: Sri Lanka, Quarterly Projection Model, Monetary Policy, Forecasting and Policy Analysis System, Flexible Inflation Targeting

Author’s E-Mail Address: chandranath@cbsl.lk; ranand@imf.org; ehelepola@cbsl.lk; hemantha@cbsl.1k; vishuddhi@.cbsl.1k; sujeetha@,cbsl.1k; kobercs13@gmail.com; tharindi@cbsl.lk; seryozha.plotnikov@gmail.com; aremo2@imf.org; poongothai@cbsl.lk; rasikay@cbsl.1k 


\section{Contents}

I. Introduction

II. Historical Background and Motivation ..................................................................... $\frac{7}{7}$

II.A. History of Economic Modelling at the CBSL ................................................ $\frac{7}{7}$

II.B. Motivation for Building a Semi-Structural Model ........................................... $\frac{10}{12}$

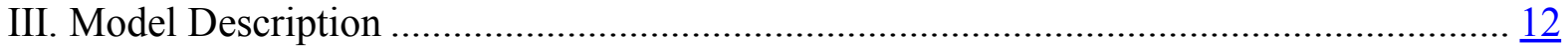

III.A. Stylized Facts of Sri Lankan Economy as Rationale for Model Design.................. $\frac{12}{13}$

III.B. Main Mechanism and Model Structure............................................................. $\frac{13}{16}$

III.C. Model Equations ...................................................................................... $\frac{16}{16}$

III.C.1. Domestic Economy ................................................................... 16

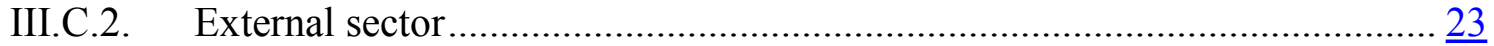

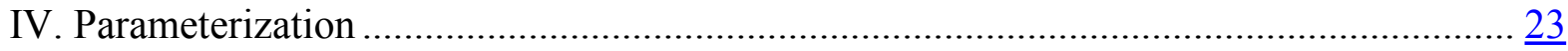

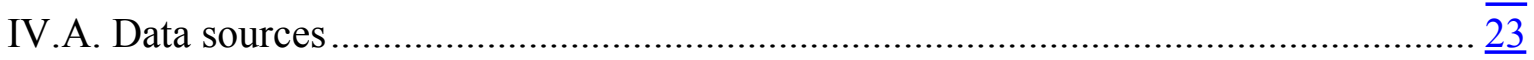

IV.B. Calibration techniques.......................................................................... $\frac{27}{29}$

IV.C. Calibration of main behavioral equations ................................................... 29

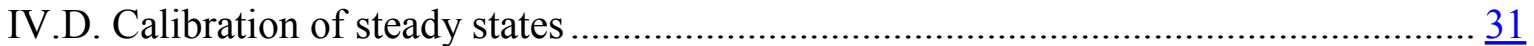

IV.E. Fine tuning calibration using Bayesian Maximum Likelihood Estimation.............. $\underline{32}$

V. Economic Implications and Model Properties .................................................. $\underline{35}$

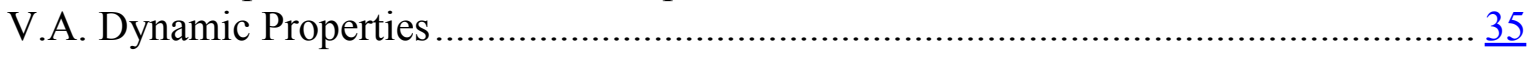

V.B. Historical Shock Decomposition........................................................................... $\frac{39}{42}$

V.C. Historical Forecast Performance .............................................................. 42

VI. Directions for Future Analysis .......................................................................... 4.

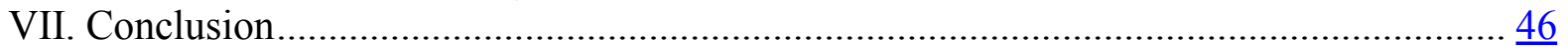

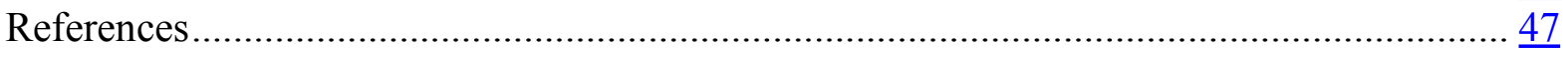

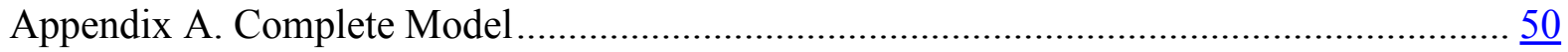

\section{Tables}

Table 1. Comparison of RMSE for Headline Inflation with........................................... 18

Table 2. Prior Distributions and Estimated Values................................................... 34

Table 3. RMSE Comparison of the Main Model Variables............................................ $\frac{35}{53}$

Table 4. Model Variables...................................................................................... $\frac{53}{56}$

Table 5. Model Structural Shocks.............................................................................. $\frac{56}{56}$

Table 6. Model Parameters ........................................................................................ $\frac{57}{57}$

\section{Figures}

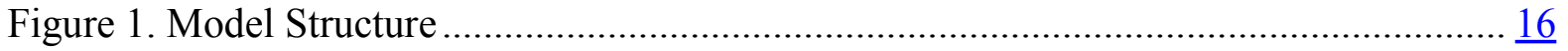

Figure 2. Impact of Civil War End on Potential Output and Risk Premium ...................... $\frac{28}{30}$

Figure 3. Domestic Headline and World Commodity Inflation ..................................... $\underline{30}$

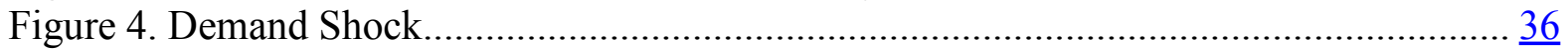

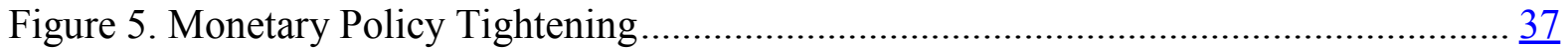

Figure 6. Temporary Exchange Rate Shock ….......................................................... $\frac{38}{39}$

Figure 7. Policy Response to the Different Supply Shocks ............................................. $\underline{39}$

Figure 8. Shock Decomposition of Annual Inflation ................................................. 41

Figure 9. Shock Decomposition of Real Output Gap ................................................. 41

Figure 10. In-sample Forecast of the Main Macro Variables ............................................ $4 \underline{43}$

\section{Boxes}

1. Handling Noisy GDP data .............................................................................. 26 
This working paper has been prepared as part of the joint capacity building project between the International Monetary Fund (IMF) and the Central Bank of Sri Lanka under the overall guidance of Mr. Andrew Berg of the IMF.

The authors wish to thank Dr. P. Nandalal Weerasinghe, Mr. K.D. Ranasinghe, and Mr. K.M.Mahinda Siriwardana of the Central Bank of Sri Lanka for their guidance. ${ }^{1}$

\footnotetext{
${ }^{1}$ The authors are also grateful for valuable comments on this working paper received from Monetary and Capital Markets, Research, and Asian \& Pacific Departments of the IMF.
} 


\section{INTRODUCTION}

The Sri Lankan economy has undergone significant economic transformation since independence. The rapid pace of structural transformation, especially in the post-conflict era, alongside attempts to carve a niche for itself in the global economy as an exporter and an investment destination poses new challenges that warrant changes to the macroeconomic framework that guides the economy. While the economy has already successfully transitioned to a floating exchange regime since 2001, the transition of the monetary policy framework from a monetary targeting (MT) framework to a flexible inflation targeting (FIT) framework is still underway, with the Central Bank of Sri Lanka (CBSL) currently undertaking monetary policy under an 'enhanced' monetary policy framework that is a hybrid of the MT and FIT frameworks.

The evolution of the CBSL into an increasingly transparent and forward-looking institution is imperative to the successful transition to FIT. Accordingly, the use of structural models for medium-term projections and policy analysis is indispensable. Such models can provide forward-looking guidance on potential monetary policy actions required to align inflation with its medium-term objective while stabilizing real output at its potential level. The model outcomes can also structure the debate about underlying assumptions, risks, and policy issues, and will permit greater transparency in policy decisions and communication (Alichi et al., 2015). Further, it must also be discerned that the underlying role for monetary policy in such a rule-like framework is to serve as an anchor for inflation and inflation expectations while the central bank exercises its discretion in its reaction to shocks (Hammond, 2012). With due consideration to the importance of communication in the management of inflation expectations, the use of a simple structural model will also enable CBSL to bridge information gaps with the public regarding the rationale of the monetary policy stance.

In this paper, we describe a basic version of a new core forecasting model to be used at the CBSL for forecasting and monetary policy analysis. The work on this new core model has 
been part of a broader joint project of the CBSL and the International Monetary Fund (IMF) on developing a modern Forecasting and Policy Analysis System (FPAS) at the CBSL. ${ }^{2}$

The FPAS project draws on best-practices in the development of these frameworks in other central banks, described extensively in Laxton et al (2009). The FPAS consists of various elements: (i) a team fully dedicated to forecasting with clearly defined responsibilities, (ii) a database infrastructure, (iii) a set of near-term forecasting and nowcasting tools, (iv) a core quarterly projection model (QPM) which embodies policymakers' view about the transmission mechanisms and relevant shocks that affect the economy, (v) a regular schedule of meetings to update the forecast and interact with senior management, and (vi) a reporting process that presents the analysis in a clear and straightforward manner to the policy makers. As the above list makes clear, the FPAS combines quantitative tools to be used by central bank staff with a set of processes to use these tools efficiently in the policy decision-making.

The central banks which adopted (flexible) inflation targeting are known to capitalize on FPAS to disciple their policy analysis. This is because the FPAS framework is not just the forecasting model but it is a comprehensive framework which involves (i) collecting and organizing key set of macroeconomic variables; (ii) developing a consistent, model-based macroeconomic forecast including measures of uncertainty and alternative risk and policy scenarios, (iii) reporting and communicating the forecast to the Monetary Policy Committee and the Monetary Board (Andrle et al., 2013). In turn, it paves way for the formulation of forward-looking policies to achieve stabilization in the medium-term (CBSL, 2017).

The remainder of this paper is organized as follows, Section II provides insight about the progress of economic modelling in CBSL and contemporary motivation for the development of a semi-structural model. Section III describes the new QPM model and the theory and practical aspects underpinning the creation of this customized model. The means of calibration and fine-tuning of the QPM is described in Section IV, followed by an analysis of the dynamic properties of the model, and assessment of the model's performance using 'in-

\footnotetext{
${ }^{2}$ A similar system has been recently adopted also at the Reserve Bank of India (Benes et al., 2016b).
} 
sample' simulations described in Section V. In Section VI, the paper proposes areas for future research and ends with concluding remarks in Section VII.

\section{HistoricAl BACKGROUND AND Motivation}

\section{II.A. History of Economic Modelling at the CBSL}

Sri Lanka gained independence in 1948, and since then, its economy has shown a gradual transformation from an agriculture based primary commodity producer into a predominantly service based light manufacturing economy. The country's per capita income has increased from around US dollars 100 at the time of independence to reach the upper threshold of the lower middle-income economy status. The CBSL, established in 1950, has been at the forefront of this gradual transformation, and contributed to maintaining economic stability while supporting economic growth. Broadly speaking, during the first 25 years of its existence, the CBSL's functions were less complex, with a fixed exchange rate system, strict capital controls, and underdeveloped domestic money and capital markets. The economy was hit by occasional external shocks, and stringent regulatory policies were introduced to mitigate the impact of such challenges. Supporting economic development, the CBSL continued to provide subsidized credit to selected sectors of the economy. However, the introduction of open economy policies in 1977 required an overhaul of the entire policymaking machinery. The CBSL key responses included the introduction of monetary targeting in the early 1980s, the automation of the clearing house, and active facilitation of the development of domestic financial markets. Whether the CBSL was successful in achieving its multiple objectives is arguable. However, judging by the available macroeconomic statistics, it appears that the economy became more volatile, and inflation cycles became larger, shrouding the achievements of the economy in the post-1977 period.

From its inception, the CBSL has taken measures to train its staff in technical aspects of economic modelling. This has been facilitated by the Monetary Law Act No 58 of 1949, which established the Economic Research Department as a core department of the CBSL and empowered the CBSL to "promote and sponsor the training of technical personnel on the subjects of money, banking, statistics, finance, and other economic subjects". Accordingly, the staff of the CBSL has been able to introduce techniques, in line with global developments 
in theoretical and empirical economic modelling, to analyze the increasingly complex Sri Lankan economy.

Early efforts to formalize technical modelling of the Sri Lankan economy could be found in three studies by the staff of the CBSL. Sirisena (1976) developed a multisectoral model of production for Sri Lanka using input-output analysis and linear programming as production planning techniques. Karunasena's work on “A Macroeconometric Model for Sri Lanka (1986)", attempted to capture the functioning of the Sri Lankan economy by building a thenpopular large scale macroeconometric model. Wijesinghe's thesis titled "Some Experiments with a Multisectoral Intertemporal Optimization Model for Sri Lanka (1986)" introduced intertemporal aspects to modelling of the Sri Lankan economy.

By late 1990s, a number of developments necessitated a serious rethinking of central banking in Sri Lanka. These included a) global developments in central banking, in particular, the view that price stability must be the overriding objective of a central bank, b) the managed floating exchange rate regime becoming unviable, c) the rapid development of financial markets and need to regulate hitherto unregulated sectors, d) financial innovation, including the development of electronic payments and fund transfer systems, together with the impending challenges from a possible "millennium bug", and e) exigencies caused by a terrorist attack in 1996 urging the CBSL to conduct its essential operations more efficiently. These developments prompted the CBSL Modernization Project, with technical and financial assistance from the IMF, the World Bank and the Sveriges Riksbank. In relation to the conduct of monetary policy, this process of modernization resulted in the establishment of the Monetary Policy Committee (MPC), floating of the Rupee, and the introduction of the system of active open market operations (active OMOs). The period that followed also saw the publication of a number of studies by the staff of the CBSL including Thenuwara (1998), Mahadeva and Thenuwara (2000), Jayamaha et al (2002), Amarasekara (2005), Weerasinghe et al (2005), Amarasekara (2008), Perera (2008 and 2009), Wimalasuriya (2009), Ratnasiri (2011), and Jayawickrema and Perera (2013). These studies focused on assessing the feasibility of inflation targeting in Sri Lanka, analyzing the transmission channels of 
monetary policy, and assessing the impact of monetary policy on key macroeconomic variables in Sri Lanka.

Supported by the findings of these studies, the Economic Research Department and the Statistics Department of the CBSL continued to provide analysis and projections of inflation and economic activity to the Monetary Policy Committee (MPC) to support its recommendations on the monetary policy stance to the Monetary Board of the CBSL. The Economic Research Department has been providing Vector Error Correction (VEC) based headline and core inflation forecasts along with fan charts with a near-term focus while the Statistics Department has been producing time series regression with ARIMA noise, missing values and outliers-signal extraction in ARIMA time series (TRAMO-SEATS) model combined with a moving average based method for near-term inflation forecasting. Both departments depend on indicator based nowcasting and near-term forecasting of economic activity, while Hodrick-Prescott (HP) and Band-Pass (BP) filter estimates of potential GDP have been provided to the MPC from time to time. Forward looking inputs to the MPC were introduced in mid-2000s with the commencement of the Inflation Expectations Survey, and a number of surveys, including the Business Outlook Survey and the Purchasing Managers' Index (PMI) Survey have been introduced recently. With the introduction of the core QPM outlined in this paper, these various sources of forward-looking information and results of the various near-term forecasting models will continue to feed into the process of forming a baseline medium-term outlook at the CBSL.

The latest developments in economic modelling in late 2000s, in particular, the introduction of DSGE modelling, have also attracted the attention of the CBSL, although the introduction of such models into the policymaking process has been slower than those observed in peer economies. Nevertheless, a number of recent studies authored by the staff of the CBSL as well as of the IMF have introduced DSGE techniques in the Sri Lankan context. These include Anand, Ding and Peiris (2011), who develop a model for inflation forecasting and evaluating policy trade-offs, Ehelepola (2014) provided welfare maximizing optimal monetary and fiscal policy rules for Sri Lanka in a DSGE framework, closely following Schmitt-Grohe and Uribe (2007), and Jegajeevan (2014) estimated a medium scale DSGE 
model using Bayesian technique to study Sri Lankan business cycles. Karunaratne and Pathberiya (2014) and Ehelepola (2015) estimated a New Keynesian Small Open Economy (SOE) DSGE model for Sri Lanka using Bayesian techniques.

The current study, which is a product of a joint project between the CBSL and the IMF attempts to build on the existing research on Sri Lanka, and produce a comprehensive small open economy quarterly projection model that can be used for practical monetary policy making in Sri Lanka.

\section{II.B. Motivation for Building a Semi-Structural Model}

The success of an inflation targeting (IT) regime mainly depends on anchoring inflation expectations at a desirable level while minimizing large fluctuations in the country's economic growth. In an IT framework, the underlying focus is on inflation. Therefore, in determining an appropriate policy stance, the most recent developments as well as probable future paths of inflation should be monitored, taking into account other numerous pressures and risks on achieving the target. Consequently, attention should be given to systematic components and other key indicators in the short-term, in order to better comprehend linkages between various macro-economic variables and the impact of policy responses.

Until recently, the CBSL has been using Vector Auto Regression (VAR) and Vector Error Correction (VEC) models to assess future developments of key macroeconomic variables, and inform monetary policy decisions. They are flexible and simple models used in policy analysis which could be used for limited structural inference. However, in the move towards the adoption of a FIT regime, it is essential that a more structured approach is employed in analyzing policy trade-offs and macroeconomic dynamics for monetary policy decision purposes. Moreover, a clear logical and a practical policy framework should be in place to support the communication of policy to the public at large. In this context, small new Keynesian models, which are increasingly used in central banks for monetary policy analysis and forecasting purposes are known to improve the decision-making process. 
Despite that FPAS at the central banks comprises always a suite of tools, models and processes that enable the conduct of comprehensive macroeconomic analysis and forecasting to feed into the decision-making process, it is usually build around one core (semi-)structural model. The unique benefits of the core model are its level of transparency and simplicity that it entails, while accommodating the analysis of the key features of an economy (Dizioli and Schmittmann, 2015). It expresses variables in terms of gaps (deviation from their long-run trend) as well as trends, making the model tractable and intuitive for monetary policy analysis. These models, in addition to being a forecasting tools, help provide economic interpretations to forecasts and related risks, and the appropriate policy responses to shocks, while providing a basis for exploring the monetary transmission mechanism and the dynamics of shocks to the economy.

The development of a (semi-)structural core forecasting model for the FPAS is therefore an essential ingredient to Sri Lanka's successful transition to FIT, and here we present a basic version of such customized semi-structural core forecasting model for the CBSL FPAS. This model will enable holistic analysis in the form of a baseline assessment, balance of risks to the baseline projections while allowing analysis of the nature of policy response to various kinds of shocks. ${ }^{3}$ To remain tractable, the model remains concise but has been designed in a structured manner to ensure that it sufficiently captures the dynamics of major macroeconomic variables and provides useful insights. Each equation in the model can be partially traced back to their theoretical underpinnings while certain aspects will strive to capture empirical traits. This will not only serve as an essential foundation to the policymakers' decision-making process but will also aid in Sri Lanka's long-term endeavor to construct a fully-fledged DSGE model. However, this model will continue to be refined and extended in a manner that will address the evolution of the economy and related challenges while ensuring that it remains agile.

\footnotetext{
${ }^{3}$ See Berg, et al. (2006) for a thorough discussion on FPAS and role of QPM in the system.
} 


\section{Model DesCRIPTION}

This section describes the QPM of the CBSL developed jointly by the CBSL staff and IMF.

Our goal was to develop a coherent and consistent framework which is suitable for producing medium-term projections and simultaneously for analyzing macroeconomic risks thus contributing to formulation of monetary policy. As such, the model embodies the policymakers' view about the monetary transmission mechanism and incorporates all relevant information from macroeconomic data. A key aspect is to introduce monetary transmission channels in the model while using a transparent and tractable structure so we kept the model's structure relatively simple. These type of quarterly forecasting models were successfully used in many other central banks in their forward-looking policy making process.

It is also important to note that this model is one of many tools (including BVARs and leading indicator models) in CBSL's FPAS but as a core model it will play a significant role in the forecasting and decision-making process.

In the rest of this section we first discuss the main features of the Sri Lankan economy relevant for the model design, then we describe the structure and the monetary transmission mechanism in the model, and at the end of this section we provide more details about the key structural equations of the model (a complete list of model equations, a glossary of variables and the parameters can be found in Appendix A).

\section{III.A. Stylized Facts of Sri Lankan Economy as Rationale for Model Design}

The CBSL is vested with the responsibility of safeguarding the value of the local currencythe Sri Lankan rupee. Since its inception, CBSL has been consistently engaged in policy measures that focus on the preservation of the internal value of the domestic currency and the fact that there is not a single episode of hyper-inflation or of crises that are of a monetary nature in the history of the economy is testimony to the efficacy and level of prudence exercised in monetary management (Wijewardena, 2007). 
For more than three decades, CBSL had pursued MT as its monetary policy framework wherein monetary aggregates served as the key nominal anchor in the conduct of monetary policy in Sri Lanka. Hence, the objective of economic and price stability was achieved by influencing an intermediate target that was defined based on broad money aggregates, which were in turn linked to reserve money through the money multiplier. Under this framework, reserve money was considered the operating target of monetary policy as outlined in the annual monetary program which is prepared based on the future path of key macroeconomic variables with due consideration to intersectoral linkages.

During this period, Sri Lanka's exchange rate policy has also gradually evolved from a fixed exchange rate regime to an independently floating regime. In 2001, the CBSL announced that it will halt trade of foreign exchange at preannounced rates, instead reserving the right to intervene in the market to buy and sell foreign exchange at or near market prices in order to curb undue volatilities in the short-term while enabling the country to build its international reserve position in the medium-term. Since then, the degree of the CBSL intervention in the foreign exchange market has varied from time to time. Nevertheless, throughout this period the exchange rate has played a key role in anchoring inflation expectations.

Over the years there has been a breakdown in the relationship between monetary aggregates and variables such as inflation. There has also been notable volatility in the money multiplier and velocity which has exerted significant uncertainty on the role of monetary targets as a nominal anchor-a development experienced in other developing countries too (IMF, 2014) Instability of the relationship between money and inflation has led to the CBSL's conduct of monetary policy within an enhanced monetary policy framework that comprises features of both money targeting and flexible inflation targeting. Again, this evolution of the policy framework is not unique to Sri Lanka, but has been observed in many developing countries (IMF, 2015).

\section{III.B. Main Mechanism and Model Structure}

The CBSL's QPM is a semi-structural small open economy model of the monetary transmission. As based on the New-Keynesian paradigm the model incorporates nominal and 
real rigidities. The model is a so-called gap model, which means that it focuses on business cycle fluctuations around an exogenously given equilibrium. The main mechanism driving inflation over the business cycle are the fluctuations of real variables (such as output and the real exchange rate) around their long-term trends. ${ }^{4}$

As a semi-structural model, the model is a short-cut for a full structural model derived from optimization (DSGE). The semi-structural model has good theoretical background but its structure is flexible enough to account for many empirical findings that would be hard to capture in a fully micro-founded DSGE model but are very important for monetary policy making in emerging markets.

The underlying mechanisms can be defined with the following four basic relationships.

- Aggregate demand depending negatively on the real interest rate and positively on real exchange rate (IS curve - Euler equation).

- Aggregate supply reacting in the short run on excess demand and prices of intermediary goods in production (New-Keynesian Phillips curve).

- The central bank which sets the path of the policy rate to achieve its inflation objective (and perhaps other objectives).

- The exchange rate determined by current and future interest rate differentials adjusted by the country risk premium (uncovered interest rate parity).

The monetary policy exerts its influence on the economy through the following channels:

- Interest rate channel: in the short run, the change of real interest rates effects the agent's intertemporal substitution between today's demand and the future demand. If the real rates are higher, agents save more and postpone their spending (e.g.

\footnotetext{
${ }^{4}$ We construct a trend-cycle decomposition for the observed real variables in the model. The levels are defined as the sum of a cyclical and a trend component (i.e. for any real variable $x=\bar{x}+\hat{x}$ where $\hat{x}$ denotes the gap (cyclical) and $\bar{x}$ denotes the trend component). It is important to note that all variables are in logarithmic terms so cyclical components are thus expressed as a percentage of the trend. The long-term real trends in the economy (or their growth) are captured by autoregressive mean-reverting processes centered around the steady states of the respective long-run relationships.
} 
consumption, investment) which leads to the reduction of the demand-side inflationary pressure.

- Exchange rate channel: The lower the central bank's policy interest rate is the less attractive domestic instruments become, thus demand for the domestic currency falls, which leads to a depreciation. On one hand this improves the competitiveness of domestically produced tradable goods, which boost economic activity resulting in a demand side inflationary pressure. On the other hand, the weaker currency makes imported commodities and other imported production factors more expensive amplifying supply-side inflationary pressures.

- Expectation channel: Monetary policy decisions have also an effect on agents' expectations of economic growth, prices and future path of interest rates. Credible and transparent monetary policy makes agents of the economy aware what measures the central bank is likely to take to mute the effect of future shocks hitting the economy and they form their expectations about future economy growth, interest rates and prices based on this. These expectations affect decisions of firms and households about current saving and investment, and price setting.

The structure of the model and the most important channels of monetary transmission are presented in Figure 1. 
Figure 1. Model Structure

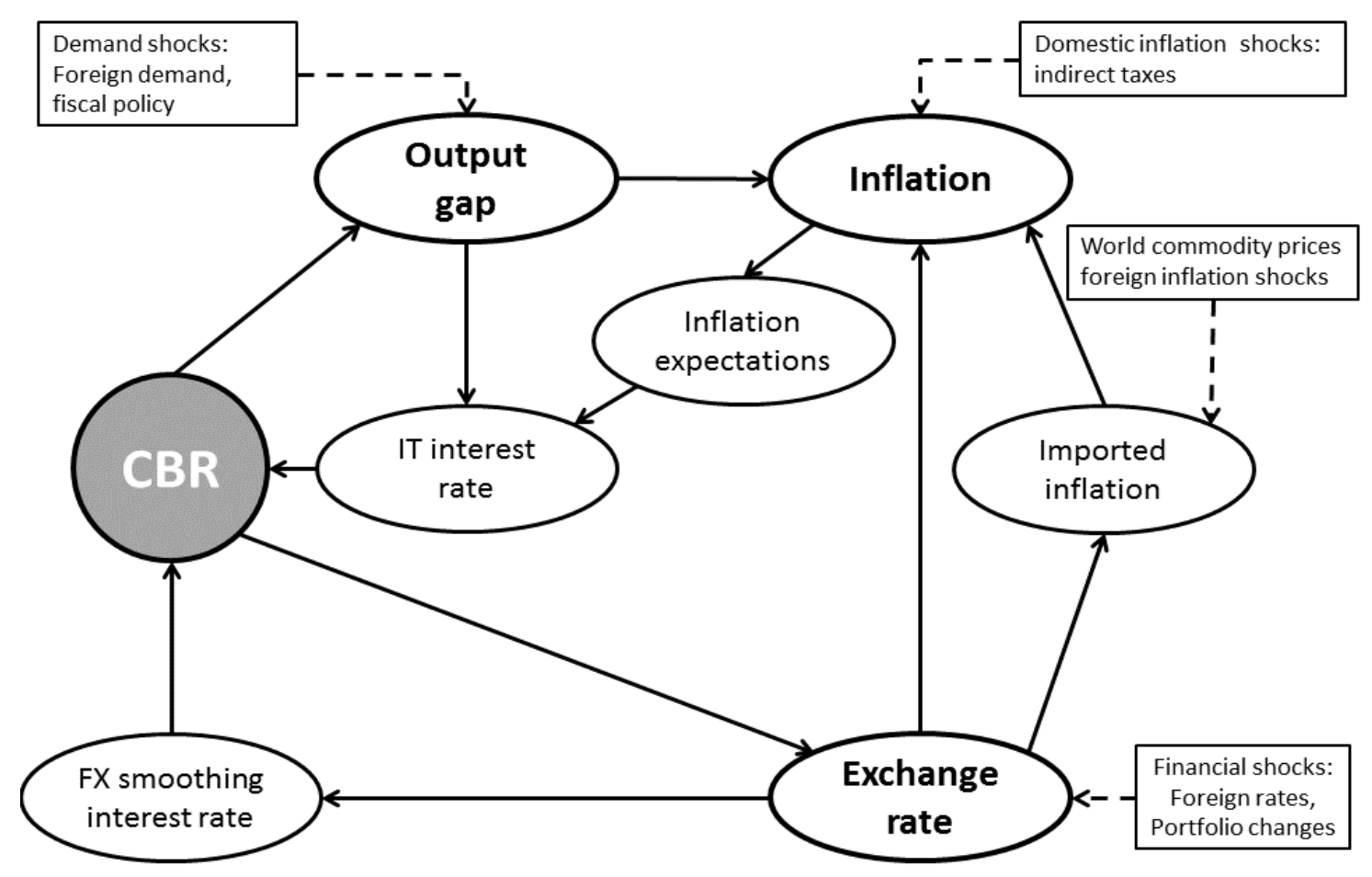

\section{III.C. Model Equations}

\section{III.C.1. Domestic Economy}

\section{Aggregate Demand}

We use the overall production to reflect the business cycle position of the economy. The aggregate demand relationship corresponds to the open-economy version of the traditional IS curve which governs the intertemporal substitution between today's demand and the future demand. It takes the following form:

$$
\hat{y}_{t}=a_{1} \cdot \hat{y}_{t-1}+a_{2} \cdot \hat{y}_{t+1}-a_{3} \cdot \hat{r}_{t}+a_{4} \cdot \hat{y}_{t}^{\text {foreign }}-a_{5} \cdot \hat{z}_{t}+\varepsilon_{t}^{\hat{y}}
$$

Where $\hat{y}_{t}$ is the deviation of the natural logarithm of output from its noninflationary levelthe output gap. In this formulation, the output gap depends on its past value $\hat{y}_{t-1}$ (which reflects real rigidities e.g. habit formation) and model-consistent expectations of its future value $E_{t}\left(\hat{y}_{t+1}\right)$. The dynamics are then driven by monetary policy through real interest rate gap, $\hat{r}_{t}$, (i.e., a deviation of the real interest rate, $r_{t}$, from the natural rate of interest $\bar{r}_{t}$ ). 
Since Sri Lanka is a small open economy its cyclical position does also depend on foreign demand, captured here by the foreign output gap, $\hat{y}_{t}^{\text {foreign }}$, and on the terms-of-trade approximated in the model by the real exchange rate gap $\hat{z}_{t}$ (i.e., a deviation of the real exchange rate, $z_{t}$, from its equilibrium level). The demand shock to the output gap is represented by $\varepsilon_{t}^{\hat{y}}$.

Equilibrium growth is modelled as an auto regressive process converging to the steady state growth rate:

$\Delta \bar{y}_{t}=a_{6} \cdot \Delta \bar{y}_{t-1}+\left(1-a_{6}\right) \cdot \Delta \bar{y}_{s s}+\varepsilon_{t}^{\Delta \bar{y}}$

\section{Aggregate Supply}

The model disaggregates the aggregate supply into three parts: producers of core consumption goods and services (representing 68.8 percent of the CPI basket), producers of volatile food (15.2 percent) and producers of regulated transport and energy goods and services (treated as the residual).

The motivation for separate modelling of the inflation components is the different relevance of the corresponding inflationary shocks for the monetary policy. Incorporating inflation components in the QPM helps to distinguish various sources of inflation as well as different dynamic properties of its components and to capture better the dynamics of the overall inflation. Table 1 shows how the forecasting performance improved after adding the inflation components into the model. 
Table 1. Comparison of RMSE for Headline Inflation with and without Inflation Components in the QPM

\begin{tabular}{|r|c|c|c|c|c|c|}
\hline \multicolumn{1}{|c|}{ Quarters ahead } & $\mathbf{1 Q}$ & $\mathbf{2 Q}$ & $\mathbf{3 Q}$ & $\mathbf{4 Q}$ & $\mathbf{5 Q}$ & $\mathbf{6 Q}$ \\
\hline $\begin{array}{r}\text { Headline Inflation, \% } \\
\text { YoY }\end{array}$ & & & & & \\
$\begin{array}{r}\text { without inflation } \\
\text { components in QPM }\end{array}$ & 1.0 & 2.0 & 2.8 & 3.4 & 3.5 & 3.4 \\
with inflation & 1.3 & 2.0 & 2.4 & 2.8 & 2.8 & 2.9 \\
\hline components in QPM & & & & & & \\
\hline
\end{tabular}

Aggregate supply in the model is represented by the Phillips-curve-type equations linking the real sector with nominal prices. Each inflation component (Core, Energy and Transportation, and Volatile Food) has its own equation comprising different set of factors. The headline inflation is the weighted average of the three components plus a discrepancy term:

$$
\pi_{t}=a_{14} \cdot \pi_{t}^{c}+a_{13} \cdot \pi_{t}^{v f}+\left(1-a_{14}-a_{13}\right) \cdot \pi_{t}^{e t}+\pi_{t}^{\text {disc }}
$$

In line with the New Keynesian approach of the model, core inflation (modeled by equation (4)) is driven by the inflationary expectations $E_{t}\left[\pi_{t+1}^{c}\right]$. Since firms can't adjust prices in fully flexible way, we include backward-looking inflation $\pi_{t-1}^{c}$ to match the observed rigidity of core prices.

$$
\begin{aligned}
\pi_{t}^{c}=a_{15} \cdot \hat{y}_{t} & +a_{16} \cdot \pi_{t-1}^{c}+\left(1-a_{16}-a_{19}\right) \cdot \pi_{t+1}^{c}-a_{17} \cdot\left(\hat{z}_{t}-a_{13} \cdot \hat{r p}{ }_{t}^{v f / c}-(1\right. \\
& \left.\left.-a_{13}-a_{14}\right) \cdot \hat{r p}_{t}^{e t / c}\right)+a_{18} \cdot r \hat{p}_{t}^{e t / c}+a_{19} \cdot \Delta p_{t}^{f o o d, i m p, c}+\varepsilon_{t}^{\pi^{c}}
\end{aligned}
$$

The costs of domestic production factors in core sector are captured by the output gap $\hat{y}_{t}$, while the costs of imported production factors are captured by sectoral effective real exchange rate gap (real exchange rate gap $-\hat{\mathrm{z}}_{\mathrm{t}}$ - adjusted by the differential between headline and core inflation). Since core basket includes food components too, and the production of core goods is energy intensive we introduced the direct effect of imported food inflation $\Delta p_{t}^{\text {food,imp,c }}$.(world food inflation in rupee adjusted by long-term sectoral price 
dynamics) and the spillover effect from domestic energy and transport prices $\widehat{r p}_{t}^{e t / c}$, where $\widehat{r p}_{t}^{e t / c}$ is the relative price of energy and transport against the core price index.

We are calculating sectoral relative prices $r p_{t}^{j}$ against the core price index. In order to better monitor changes in relative prices we construct a trend-gap decomposition. For all sectors, we assume that relative prices are converting back to their long-term trend (i.e. the cyclical components will close over the forecast horizon).

The relative price in sector $j$ is defined as:

$$
r p_{t}^{j}=p_{t}^{j}-p_{t}^{c}
$$

where $p_{t}^{j}$ is the log level of prices in sector $j$ and $p_{t}^{c}$ is the log level of prices in the core sector. The relative price is decomposed into a gap and trend components:

$$
r p_{t}^{j}=\widehat{r p}_{t}^{j}+\overline{r p}_{t}^{j}
$$

Where $\widehat{r p}_{t}^{j}$ refers to the cyclical component of relative prices and $\bar{r} \bar{p}_{t}^{j}$ to its trend component which growth evolves according to an auto regressive process converging to its steady state growth

$$
\Delta \overline{r p}_{t}^{j}=a \cdot \Delta \overline{r p}_{t}^{j}+(1-a) \cdot \Delta \overline{r p}^{j}+\varepsilon_{t}^{\overline{r p}_{t}^{j}}
$$

Sri Lanka is an oil importer country, and thus administered energy and transport inflation depends on the world oil price dynamics. We capture this relationship by introducing the direct effect of imported oil price inflation $\Delta p_{t-1}^{\text {oil,imp,et }}$ (world oil inflation in rupee adjusted by long-term sectoral price dynamics) in the Phillips curve of Energy and Transport inflation (equation (5)). Inflationary pressure from sectoral real costs are captured by the real oil price gap $\hat{q}_{t-1}^{\text {oil,et }}$. For each commodity sector we assume that sectoral relative prices (calculated against core prices) can't deviate permanently from a long-term trend thus we introduced the sectoral relative price gap $\widehat{r p}_{t-1}^{e t / c}$ as a correction term in the Philips curve. 


$$
\begin{gathered}
\pi_{t}^{e t}=a_{22} \cdot \pi_{t-1}^{e t}+\left(1-a_{22}-a_{23}\right) \cdot \pi_{t+1}^{e t}+a_{23} \cdot \Delta p_{t-1}^{o i l, i m p, e t}+a_{24} \cdot \hat{q}_{t-1}^{\text {oil,et }}-a_{25} \\
\cdot \hat{r p} p_{t-1}^{e t / c}+\varepsilon_{t}^{\pi^{e t}}
\end{gathered}
$$

Meanwhile volatile food inflation $\pi_{t}^{v f}$ is modeled as a mean reverting process plus the adjustment with the sectoral relative price gap $\widehat{r p}_{t-1}^{v f / c}$ :

$$
\pi_{t}^{v f}=a_{20} \cdot \pi_{t-1}^{v f}+\left(1-a_{20}\right) \cdot \bar{\pi}_{t}^{v f}-a_{21} \cdot \hat{r p}_{t-1}^{v f / c}+\varepsilon_{t}^{\pi^{v f}}
$$

\section{Monetary policy rule and the uncovered interest rate parity}

Since the CBSL has multiple objectives the monetary policy in the model is described as combining two policy rules - an interest rate rule for inflation and growth objectives and an exchange rate rule for smoothing of the exchange rate.

\section{Inflation and output objective}

The first rule assumes that the CBSL's action is primarily aimed at stabilizing inflation and output. It's important to note that it does not mean that the CBSL follows an inflationtargeting regime in the strict sense of a monetary policy strategy. This type of monetary policy adjusts the nominal interest rate to influence credit conditions and exchange rate, with a view to bring inflation to desired range or target and output to its potential (noninflationary) level.

The specification of the interest rate rule is following:

$i_{t}^{p o l}=a_{7} \cdot i_{t-1}+\left(1-a_{7}\right) \cdot\left(i_{t}^{\text {neu }}+a_{8} \cdot \hat{\pi}_{t}+a_{9} \cdot \hat{y}_{t}\right)+\varepsilon_{t}^{i}$

$\hat{\pi}_{t}=\pi_{t+4}-\bar{\pi}_{t}$

$i_{t}^{n e u}=\bar{r}_{t}+\pi_{t+1}^{4}$

Where $i_{t}^{p o l}$ represents the (annualized) short-term interest rate which is consistent with an inflation and output stabilization objective. We assume that the CBSL adjusts short-term interest rates $\left(i_{t-1}\right)$ smoothly and reacts on the expected deviation of CPI inflation from the inflation objective- $-\widehat{\pi}_{t}$ is the difference between expected future inflation $E_{t}\left(\pi_{t+4}\right)$ and the inflation objective $\bar{\pi}_{t}$ (see (7a)). The reason for including a forward-looking inflation term 
into the rule is to avoid excess volatility by ignoring short-term transitory inflationary shocks and to capture the transmission lag of monetary policy.

Furthermore, the CBSL stabilizes the output at its sustainable level. This is captured by the reaction of the interest rate on the current output gap $\hat{y}_{t}$.

The interest rate is also determined by the policy-neutral rate, $i_{t}^{\text {neu }}$, which is the rate of interest that does not cause any demand pressures. It is the sum of the real neutral rate of interest and model-consistent inflation expectations (7b).

The uncovered interest rate parity condition (UIP) describes the dynamics of the exchange rate consistent with the inflation-targeting interest rates:

$i_{t}^{\text {pol }}=i_{t}^{\text {foreign }}+4\left(s_{t}^{e}-s_{t}^{u i p}\right)+\rho_{t}+\varepsilon_{t}^{\Delta s}$

where $s_{t}^{u i p}$ is the nominal exchange rate consistent with the interest rate $i_{t}^{p o l} ; s_{t}^{e}$ is the modelconsistent expectation of the nominal exchange rate; $i_{t}^{\text {foreign }}$ is the (annualized) foreign nominal interest rate; $\rho_{t}$ is the risk premium; and $\varepsilon_{t}^{\Delta s}$ is the exogenous innovation to the exchange rate. The UIP implies that the expected depreciation of the currency must equal the interest rate differential adjusted by risk premium so there is no arbitrage between investing money domestically or abroad.

\section{Exchange rate smoothing objective}

The second policy rule assumes that the primary objective of the CBSL is to smooth exchange rate movements. This type of monetary policy adjusts the nominal interest rate to influence exchange rate with a view to smooth movements of the exchange rate.

The annualized short-term interest rate consistent with this regime is derived from the UIP condition:

$$
\begin{aligned}
& i_{t}^{u i p}=i_{t}^{\text {foreign }}+4 \cdot\left(s_{t}^{e}-s_{t}^{p o l}\right)+\rho_{t}+\varepsilon_{t}^{\Delta s} \\
& \Delta s_{t}^{\text {pol }}=4 \cdot\left(s_{t}^{\text {pol }}-s_{t-1}\right)
\end{aligned}
$$


Where $i_{t}^{\text {uip }}$ and $s_{t}^{\text {pol }}$ represent the (annualized) short-term interest rate and the desired level of exchange rate respectively which are consistent with the exchange rate smoothing objective so the desired level of exchange rate is equal to the quarterly depreciation target $\left(\Delta s_{t}^{p o l}\right)$ plus the lagged level of exchange rate (9a).

The quarterly depreciation target is set by a simple exchange rate rule

$\Delta s_{t}^{p o l}=a_{10} \cdot \Delta s_{t-1}^{p o l}+\left(1-a_{10}\right) \cdot\left(-\Delta \bar{z}_{t}+\bar{\pi}_{t}-\pi_{s s}^{\text {foreign }}+a_{11} \cdot \hat{z}_{t-1}\right)+\varepsilon_{t}^{\Delta s}{ }^{p o l}$

As in the case of the interest rate we assume that the CBSL adjusts its depreciation target smoothly but in the long-term equilibrium it should be set consistently with the inflation target.

\section{The policy rate}

The actual short-term policy rate is then a combination of the two different rates defined above.

$i_{t}=a_{12} \cdot i_{t}^{p o l}+\left(1-a_{12}\right) \cdot i_{t}^{u i p}$

This formula allows the policymaker to choose between its objectives in a flexible way. Parameter $a_{12}$ reflects the relative importance of the inflation objective in the policymaker's preferences. In the extreme case when this parameter is equal to 1(0) the Central Bank follows a fully inflation targeting (exchange rate smoothing) regime.

It's easy to show that the current level of exchange rate is also a combination of the two exchanges rates under the two different regimes:

$s_{t}=a_{12} \cdot s_{t}^{u i p}+\left(1-a_{12}\right) \cdot s_{t}^{p o l}$

\section{Real exchange rate and long run UIP}

The real exchange rate is calculated against the US dollar and is defined as the nominal exchange rate adjusted for price level differential. Moreover, relative purchasing power parity relates domestic and foreign inflation rates to the change in the exchange rate.

$z_{t}=p_{t}-s_{t}-p_{t}^{\text {foreign }}$ 
The model also satisfies the long-run version of the UIP (Eq 13) expressed in real terms and equilibrium values of these variables:

$\bar{r}_{t}=\bar{r}_{t}^{\text {foreign }}-\Delta \bar{z}_{t+1}+\rho_{t}$

The equation determines the equilibrium level of the domestic neutral real interest rate $\bar{r}_{t}$ in relation to the foreign neutral rate $\bar{r}_{t}^{\text {foreign }}$, the equilibrium real exchange rate depreciation $\Delta \bar{z}_{t}$, and the risk premium, $\rho_{t}$, respectively. ${ }^{5}$

\section{III.C.2. External sector}

As the purpose of the model is not to provide forecast of the external sector variables, we model the dynamics of the external variables very simply. Moreover, since Sri Lanka is a small price-taker economy, we consider external sector as fully exogenous. The block includes U.S. output gap, U.S. CPI inflation and U.S. interest rates as approximations to global demand, inflationary pressures and global liquidity conditions. It also includes world oil and food prices. The variables are assumed to be captured by autoregressive meanreverting processes centered on the steady states of the respective long-run relationships. The complete list of external sector equations is shown in Appendix A.

\section{Parameterization}

\section{IV.A. Data sources}

The study uses data on key macroeconomic variables for Sri Lanka, namely real GDP, Colombo Consumer Price Index (CCPI) and its components, nominal interest rate (Average Weighted Call Market Rate), nominal exchange rate (US\$/Rs). Foreign data include Fed Fund rate, Brent oil price, FAO world food price index, etc. Except for GDP and Inflation related data that are obtained from the DCS, all other domestic data are obtained from the CBSL. Foreign data are from sources as listed in 4 . Forecasts of foreign variables were

\footnotetext{
${ }^{5}$ The variables on the right-hand side of equation (13) are modeled as autoregressive mean-reverting processes centered on the steady states.
} 
obtained from Mantis forecast database. All variables subject to seasonality are seasonally adjusted using X12 software package.

In the instances where data are available under different base years, a combined data series is generated using splicing technique. We extended available historical range of inflation components series using inflation data based on the previous methodology of the Department of Census and Statistics (DCS). DCS has from time to time changed the methodology and the base years of estimating key macroeconomic variables that it compiles without corresponding revisions to the previously compiled historical data. In the absence of officially published continuous data series for GDP and inflation, researchers are compelled to resort to various techniques to derive uninterrupted series largely in line with previously published data. We have therefore implemented technical tools helping to overcome this issue of break in the data series and consistently calculated historical series reflecting the recent base year and the compilation methodology. Accordingly, continuous inflation series is obtained by rebasing the historical series. The combined observed GDP data series is obtained by rebasing GDP levels based on the base years 1996 and 2002 to the new base year 2010. In the meantime, noise in the combined series is treated by adding a measurement error component to the GDP equation. The model based GDP series, named as adjusted GDP, is obtained after removing measurement error from the observed combined GDP data series. This treatment is explained in detail in the Box 1. Sri Lankan authorities are currently working with international agencies, including the IMF, to improve the quality of macroeconomic data compiled by DCS. 
Table 4. Summary of the Data used in the Model

\begin{tabular}{|c|c|c|}
\hline Variable & $\begin{array}{l}\text { Notation in } \\
\text { the Model }\end{array}$ & Data Source \\
\hline \multicolumn{3}{|l|}{ Domestic Block } \\
\hline Real Gross Domestic Product & 1_y & DCS \\
\hline Colombo Consumer Price Index & 1_cpi & DCS \\
\hline Core Inflation & 1_cpi_core & DCS \\
\hline Volatile Food Inflation & 1_cpi_vfood & DCS \\
\hline Energy and Transport Inflation & 1_cpi_et & DCS \\
\hline Average Weighted Call Money Rate & $\mathrm{rn}$ & CBSL \\
\hline Nominal LKR per USD Exchange Rate & 1_s & CBSL \\
\hline \multicolumn{3}{|l|}{ Foreign Block } \\
\hline Fed Funds Rate & $\mathrm{rn}_{-} \mathrm{f}$ & FRED Federal Reserve Bank of St. Louis \\
\hline U.S. Output Gap & 1_y_gap_f & Mantis \\
\hline U.S. CPI & 1_cpi_f & OECD statistics \\
\hline Brent Oil Price & 1_oil & Bloomberg \\
\hline FAO Food Price Index & 1_food & FAO \\
\hline
\end{tabular}




\section{Box 1. Handling Noisy GDP data}

GDP estimation is a strenuous process that faces a tradeoff between estimates accuracy and its timeliness. GDP estimates, therefore, are released on scheduled timelines and are subjected to revision later. At present, real GDP compilation in Sri Lanka is carried out by the Department of Census and Statistics in compliance with the guidelines of the Systems of National Income Accounting (SNA) 2008. The first set of real GDP estimate for a particular quarter is released by the DCS approximately ten weeks after that quarter has ended. As the revision policy is in place, these estimates are subjected to revise not more than six times during three years from the first release of particular estimates. Table 1 shows available quarterly GDP revisions in Sri Lanka.

Table 5. Quarterly Gross Domestic Product at Constant (2010) Prices: 2015

\begin{tabular}{ccccc}
\hline \hline & $\mathrm{Q}_{1} 2015$ & $\mathrm{Q}_{2} 2015$ & $\mathrm{Q}_{3} 2015$ & $\mathrm{Q}_{4} 2015$ \\
\hline First release & 6.0 & 6.7 & 4.8 & 2.5 \\
$1^{\text {st }}$ Revision & 4.4 & 6.0 & 5.6 & \\
$2^{\text {nd }}$ Revision & 4.9 & 7.0 & & \\
$3^{\text {rd }}$ Revision & 4.4 & & & \\
\hline \hline
\end{tabular}

As has been illustrated in Table B. 1, initial GDP estimates, which are mainly based on incomplete and preliminary information, can be substantially different from its revisions due to the noise and the news associated with the GDP compilation process. However, as this data inconsistency could affect policy making process, it is necessary to handle noise in GDP data in macroeconomic modeling and forecasting exercises.

Variety of methods has been applied to address the noise macroeconomic data. Filter based methods, state space and factor models are among commonly used methods. In early period, Kalman filter which allows the estimation process to adjust as and when revised data are available, has been used to address noisy economic data (Howrey, 1978). Another possible ways of handling noisy GDP data in macroeconomic modelling is to use a state space model where the measurement equation becomes an integral part of the estimation.

However, success of the forecasts based on state space models heavily depends on the structure of the measurement equations imposed. Weakly-structured measurement equations will result in less accurate forecasts than if noise in the data were ignored (Ghosh and Lien, 2001; Fukuda, 2007).

Use of factor models in macroeconomic modelling and forecasting also minimizes the impact of noise in the data generating process. These models are based on the view that a common factor can generate idiosyncratic movements in many different variables. Therefore, when noise in one data series is not correlated across variables in the model, factor models reduce the effect of noisy data on macroeconomic modelling and forecasting (Bernanke and Bovin, 2003). However, it is also argued that, in factor models the noise added from using several variables may cost more than benefits in macroeconomic modelling (Faust and Wright, 2009). The presence of noisy data, in general, makes modelling and forecasting complicated. This issue becomes crucial when dealing with a critical macroeconomic variable such as real GDP, where the effect of 'noise' on modeling and forecasting is substantial.

In order to address this issue of noisy GDP data, the QPM introduces an additional variable for GDP named 'Adjusted GDP' which is considered as the actual level of GDP free of any noise. The GDP figures published by DCS are considered as observed GDP in the model and observed GDP adjusted for noise is given as an input to the transition equations in the model. The GDP measurement error is computed within the model during the filtration stage.

\section{(C)International Monetary Fund. Not for Redistribution}




\section{IV.B. Calibration techniques}

Instead of estimating the model parameters, similar to other central banks that adopted these type of models, we calibrate them because the estimation of small, semi-structural models for developing countries faces several limitations. In these countries, including Sri Lanka, the data samples are typically very short and noisy and include structural breaks making identification more difficult for even the small-scale QPM. ${ }^{6}$ Thus estimating even our model which has about 50 parameters (including standard deviations of shocks) and on the top of that consists of several unobserved variables that must be estimated would not be advisable.

In case of Sri Lanka, the civil war which ended in May 2009 represents a particularly distinctive structural break. Admittedly, the QPM is not capable of accounting for structural breaks explicitly, or of shedding a light on drivers and dynamic of structural changes in the Sri Lankan economy. Its relatively modest structure and focus on deviations (i.e. gaps) from long-term equilibria and linear nature of the model make it not directly suitable for capturing these structural changes. That being said, the QPM has been useful to identify an increase in potential output and decline in country risk premium (and subsequent real exchange rate appreciation) which we largely attribute to improving economic prospects following the peace. Figure 2 shows a temporary increase in potential output growth of about 1.5 percentage points right after the end of the war. At about the same time, the risk premium was trending down from its peak of 6 percentage points per annum in 2007 to around 2 percentage points per annum in 2013.

\footnotetext{
${ }^{6}$ For example, our sample consists of data for a period between 2001 and 2015. This means that we have about 14 years of quarterly data (56 data points), including the periods affected by the civil war in Sri Lanka which ended in May 2009, and the global financial crisis which emerged in 2007.
} 
Figure 2. Impact of Civil War End on Potential Output and Risk Premium
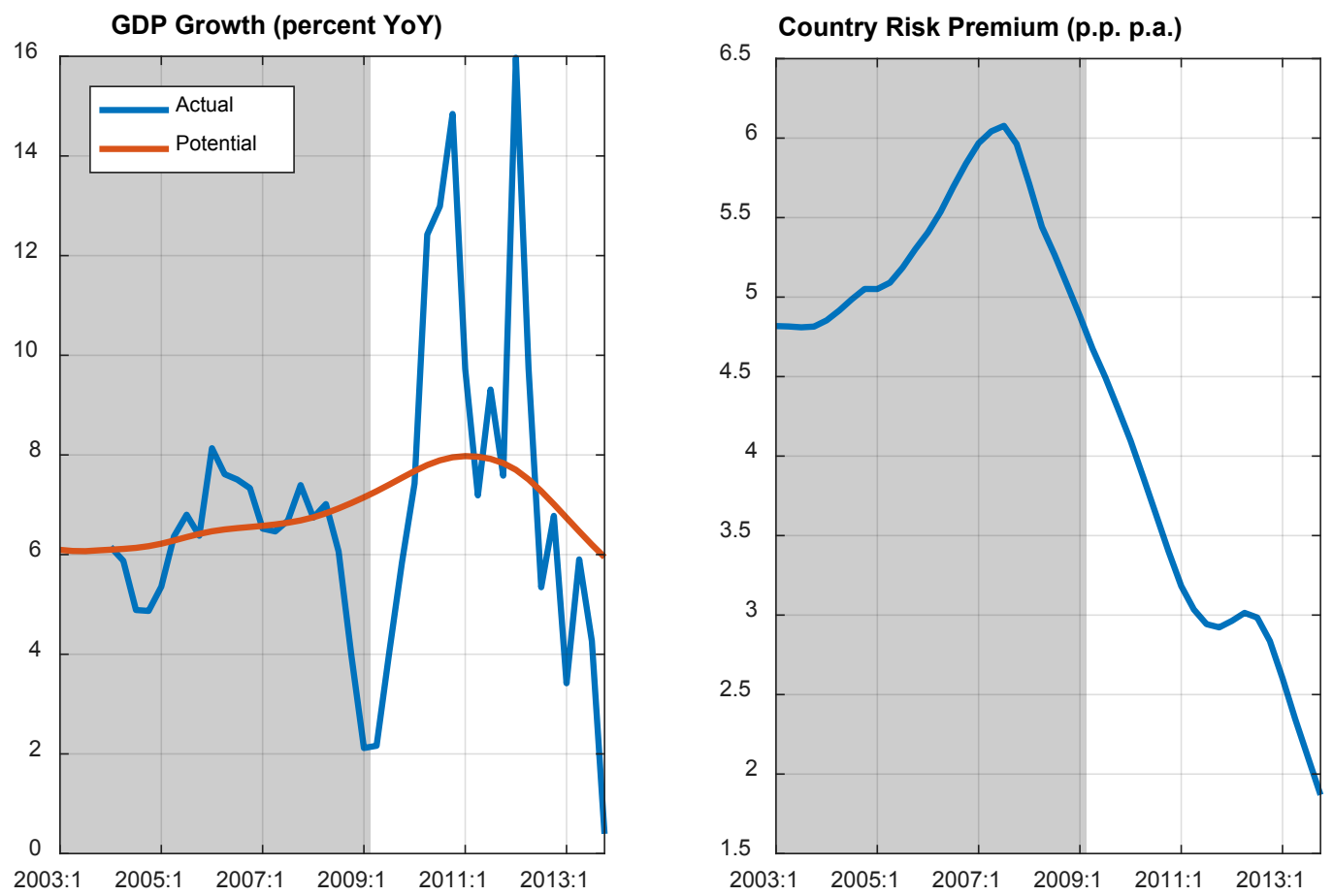

Despite the above-mentioned limitations of the QPM in capturing structural changes, we have been conscious of the civil war while calibrating the model. When assessing the model calibration using various tools mentioned below, we have been putting more emphasis on the model performance after the civil war than before 2009.

Despite of the fact that we did not estimate the model for the reasons mentioned above, calibration is still a long iterative process. In every iteration step the model's calibration is examined using several diagnostic tools until a satisfactory calibration is achieved.

These tools are:

- Impulse response functions for assessing dynamic properties of the model.

- In-sample historical forecast simulations for assessing model's forecasting performance.

- Filter decomposition to compare model's interpretation of the past events with experts' views and stylized facts. 
The results of these diagnostic tools are discussed in Section V.

\section{IV.C. Calibration of main behavioral equations}

Modelling experience of other countries, particularly emerging markets, were analyzed to choose parameter values for Sri Lanka. However, characteristics of the Sri Lankan economy and policy-making were considered when adapting parameter values for the Sri Lankan context.

The coefficient on lagged output gap in the output gap equation depends to a large extent on the degree of output inertia in the economy, the effectiveness of monetary policy transmission, and the openness of the economy. Berg, Karam, and Laxton (2006) suggest that the value of the coefficient on lagged output lies between 0.5 and 0.9 , with a lower value for less mature economies more susceptible to volatility. For Sri Lanka, we choose a value of 0.6 taking into account the emerging developments of the Sri Lankan economy. The coefficient on expected output gap is typically small, and we choose a value of 0.3 for Sri Lanka. The parameter of real interest rate gap depends on the effectiveness of the monetary transmission mechanism, while the parameters on real exchange rate gap and foreign output gap depend on the importance of the exchange rate channel and the degree of openness. We selected relatively low values for the above three parameters reflecting Sri Lanka's relatively weak interest rate channel, tightly managed exchange rate regime, and non-diversified export dependence.

Inflation dynamics in the economy were modelled using the three Phillips Curve equations, each of which individually tracks the movements in core inflation, volatile food inflation and energy and transport inflation, respectively. In the Phillips Curve equation for core inflation, the parameter on output gap depends on how much core inflation is influenced by real demand pressures, and affects the 'sacrifice ratio' of the economy. We selected a value of 0.27 for this parameter since price dynamics of core items are mainly driven by domestic excess demand. We set the parameter on backward component in the core inflation equation relatively small at 0.25 , to match the high volatility of the observed data. As Sri Lanka is an open economy, the imported inflation components have strong effect on core prices too. We 
set the parameter of real exchange rate to 0.15 resulting in a strong pass-through of the exchange rate which is in line with the past experience. Furthermore, as an energy intensive sector we set the spillover effect from energy prices to 0.06 . Since the weight of non-volatile food prices is small in the core basket we set the direct effect of imported food price dynamics to 0.02 .

Domestic administered energy inflation follows world oil price dynamics (see Figure 3) tightly thus we set relatively high parameters on the imported inflation components $(0.25)$ and sectoral real marginal costs (0.5) in the Phillips Curve for Energy \& Transport inflation. Consequently, we also observe a little price rigidity in this sector which is captured by a small parameter $(0.1)$ on the backward component.

Volatile food inflation was parameterized to respond to its lagged value, however it is assumed that volatile food inflation reverts to its long-term trend fast and thus a higher weight was assigned for the respective parameter.

Figure 3. Domestic Headline and World Commodity Inflation

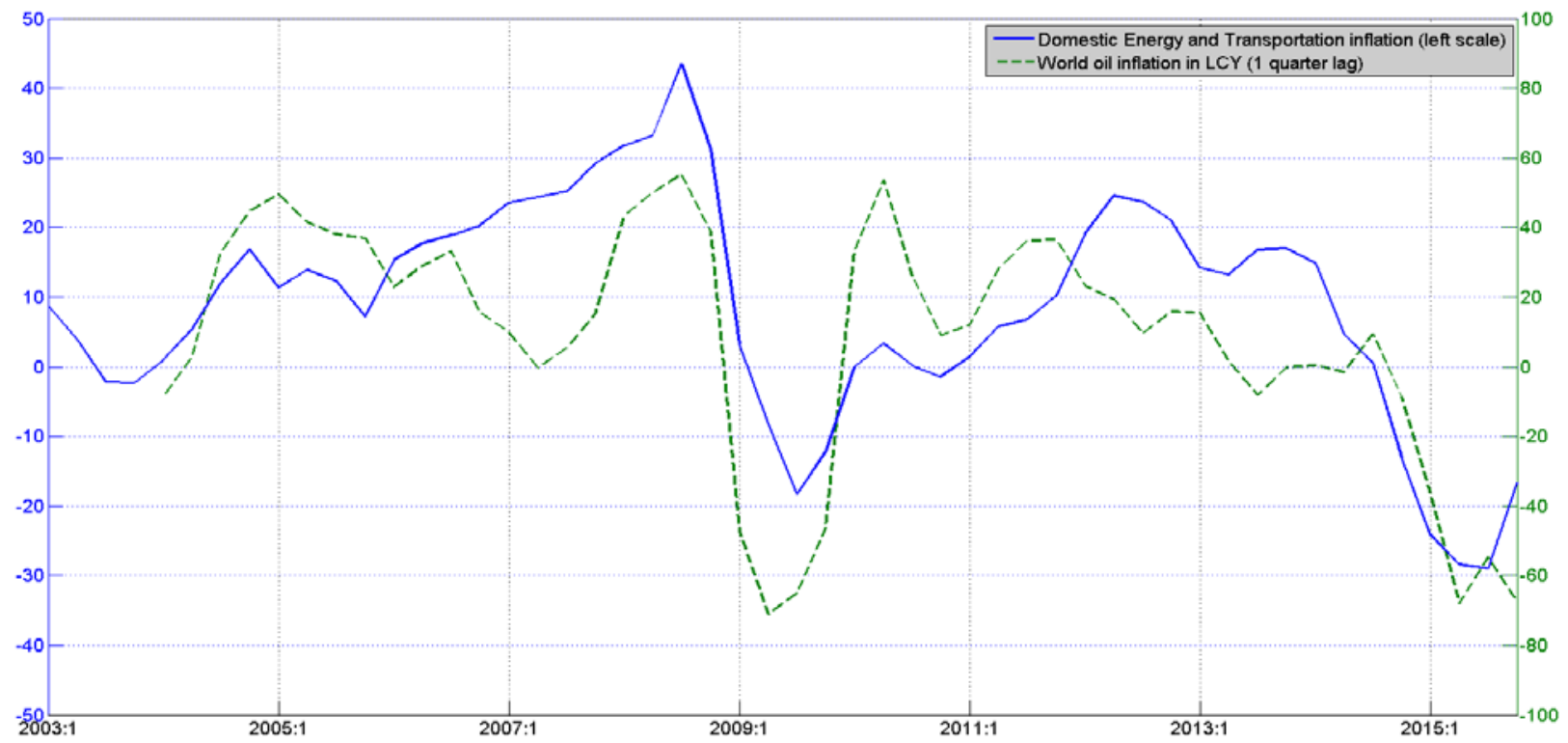

The parameters in the interest-rate monetary policy rule equation depend on the speed with which the central bank adjusts the nominal interest rate, and the relative importance of the 
inflation target versus the real economic activity target. We choose a value of 0.8 for the parameter on inflation gap, in line with the CBSL's gradual move towards a flexible inflation targeting regime (FIT), while a value of 0.1 was chosen for parameter on output gap. Reflecting the smooth path of the interest rate in the past, we set the interest rate smoothing parameter high to 0.8 . This value is also in line with the estimates of this parameter for emerging markets by Mohanty and Klau (2004).

The weight on inflation-targeting interest rate rule as opposed to the exchange rate rule (parameter $a_{12}$ ) was set to 0.8 . Thus, the calibrated value does still capture the CBSL's partial attention to the exchange rate volatility. Going forward, the parameter would be subject of revision(s) along the progressing transition to FIT which will decrease and ultimately eliminate exchange rate rule. Moreover, as the CBSL adopts FIT and the new framework gains credibility, it would be realistic to expect stronger anchoring of inflation expectations around the medium-term inflation target. In such a case, the calibration of the Phillips curves driving inflation dynamics would need to be revisited potentially increasing weights on their forward-looking components. Similarly, a build-up in policy credibility, emphasis on interest rate operational target, and inflation as nominal anchor may require in the future recalibration which would strengthen interest rate channel and weaken exchange rate channel of monetary policy transmission (parameters at the real interest rate and real exchange rate gaps in the IS curve and parameters driving exchange rate pass-through in Phillips Curves and core Phillips Curve in particular).

\section{IV.D. Calibration of steady states}

The steady state of inflation rate is set to 5 percent which coincides with the recent mediumterm inflation targets of the CBSL. This rate is also consistent with stable inflationary periods (since 2009) of Sri Lankan economy. Since we are not expecting permanent differences in price dynamics of CPI components we set the same steady state inflation for all sectors.

The steady state of the real GDP growth rate is calibrated at 6.0 percent. The country achieved over 8 percent growth rates temporarily after the end of the internal conflict, but adverse weather conditions coupled with foreign economy contractions resulted in growth 
rates moderating around 3-5 percent. The economy grew at an average rate of 6.0 percent since 2003 which is also consistent with the stable growth rates observed in the early 2000's. The steady state value of real exchange rate appreciation was set to 2 percent. The real exchange rate appreciated by approximately 2.6 percent per annum on average, but we anticipate somewhat lower rate in long-term equilibrium based on the recently observed convergence. The real exchange rate appreciation (together with the 5 percent steady state for domestic inflation and 2 percent for foreign inflation) results in a 1 percent nominal depreciation in steady state. The country risk premium was calibrated at 5 percentage points per annum to match the historical levels of interest rate differential.

The steady states of the external sector variables were set consistently with figures in the DSGE literature or to the historical averages of the respective variables. Consequently, the steady state of foreign inflation was set to 2 percent, steady state of foreign real interest rate to 1 percent, and steady state of inflation of real oil and food prices to 7.5 percent and 7 percent, respectively.

\section{IV.E. Fine tuning calibration using Bayesian Maximum Likelihood Estimation}

Application of Bayesian methods in DSGE models became very popular during the last two decades owing to the main desirable attributes they possess. ${ }^{7}$ Bayesian approach uses the likelihood function generated by the solution of the DSGE model in estimation and additional information can be incorporated into the parameter estimation by using prior distributions. That way, Bayesian technique falls in between calibration and maximum likelihood estimation. Providing a prior value is related to calibration practice while maximum likelihood method is connected to estimating the model with data. Priors can be viewed as weights on the likelihood function used to give more prominence on the desired parts of the parameter subspace. Well-known Bayes' theorem links the prior with the likelihood function, establishing the posterior density.

\footnotetext{
${ }^{7}$ See Lubik and Schorfheide (2006) and An and Schorfheide (2007) for more details.
} 
In our case, we have used Bayesian estimation merely to fine-tune our calibration. After thorough initial calibration of the model based on analysis of the various model properties (in-sample simulations, shock response functions, and model's interpretation of history) we run Bayesian Estimator with relatively narrow priors centered on the calibrated values. The purpose is to find a point in the close neighborhood of the calibration which explains the data better, but does not deviate from the calibrated values too much. A subset of key parameters selected from Table 6 are estimated for which the prior distributions and estimated values are given in Table 2 . 
Table 2. Prior Distributions and Estimated Values

\begin{tabular}{|c|c|c|c|c|c|c|}
\hline Parametert & Density & $\mathrm{P}(\mathbf{1})^{*}$ & $\mathrm{P}(2)^{*}$ & $\mathrm{P}(3)^{*}$ & $\begin{array}{l}\text { Calibrated } \\
\text { Value* }\end{array}$ & $\begin{array}{l}\text { ML } \\
\text { Estimate }\end{array}$ \\
\hline$a_{1}$ (c1_I_y_gap) & Beta & 0.1 & 0.9 & 0.05 & 0.60 & 0.5480 \\
\hline$a_{2}$ (c2_I_y_gap) & Beta & 0.1 & 0.9 & 0.05 & 0.30 & 0.2000 \\
\hline$a_{3}$ (c3_I_y_gap) & Beta & 0.001 & 0.6 & 0.01 & 0.05 & 0.0354 \\
\hline$a_{4}$ (c4_I_y_gap) & Beta & 0.001 & 0.6 & 0.01 & 0.10 & 0.0938 \\
\hline$a_{5}$ (c5_I_y_gap) & Beta & 0.001 & 0.6 & 0.01 & 0.08 & 0.0637 \\
\hline$a_{7}$ (c1_rn) & Normal & 0.2 & 0.99 & 0.01 & 0.80 & 0.8133 \\
\hline$a_{8}$ (c2_rn) & Beta & 0.01 & 0.9 & 0.07 & 0.80 & 0.7744 \\
\hline$a_{9}$ (c3_rn) & Beta & 0.0 & 0.9 & 0.01 & 0.10 & 0.0988 \\
\hline$a_{11}$ (c2_dl_s_pol) & Normal & 0.1 & 3 & 0.07 & 1.00 & 0.8220 \\
\hline$a_{12}$ (w_rn_rule) & Normal & 0.1 & 0.99 & 0.03 & 0.80 & 0.8066 \\
\hline$a_{26}$ (c1_dl_cpi_disc) & Uniform & 0.0 & 0.99 & $1 / 12$ & 0.50 & 0.0787 \\
\hline$a_{15}$ (c1_dl_cpi_core) & Beta & 0.1 & 0.99 & 0.02 & 0.27 & 0.2509 \\
\hline$a_{16}$ (c2_dl_cpi_core) & Beta & 0.0 & 0.99 & 0.02 & 0.25 & 0.2743 \\
\hline$a_{17}$ (c3_dl_cpi_core) & Beta & 0.001 & 0.99 & 0.01 & 0.15 & 0.1366 \\
\hline$a_{18}$ (c4_dl_cpi_core) & Beta & 0.001 & 0.6 & 0.01 & 0.06 & 0.0435 \\
\hline$a_{19}$ (c5_dl_cpi_core) & Beta & 0.001 & 0.6 & 0.01 & 0.02 & 0.0288 \\
\hline$a_{20}$ (c1_dl_cpi_vfood) & Normal & 0.0 & 0.99 & 0.1 & 0.10 & 0.2680 \\
\hline$a_{21}$ (c2_dl_cpi_vfood) & Normal & 0.0 & 4 & 0.2 & 2.00 & 1.2902 \\
\hline$a_{22}$ (c1_dl_cpi_et) & Normal & 0.0 & 0.99 & 0.1 & 0.10 & 0.2089 \\
\hline$a_{23}$ (c2_dl_cpi_et) & Beta & 0.0 & 0.9 & 0.05 & 0.25 & 0.1807 \\
\hline$a_{24}$ (c3_dl_cpi_et) & Normal & 0.0 & 2 & 0.1 & 0.50 & 0.1664 \\
\hline$a_{25}$ (c4_dl_cpi_et) & Normal & 0.0 & 4 & 0.1 & 0.50 & 0.4487 \\
\hline$a_{31}$ (c1_e_l_s) & Beta & 0.2 & 0.999 & 0.01 & 0.90 & 0.8722 \\
\hline
\end{tabular}

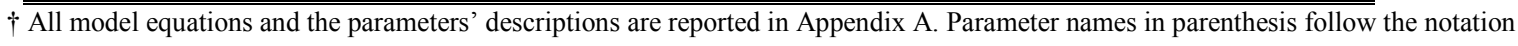
adopted in the actual model code.

* Note: $\mathrm{P}(1), \mathrm{P}(2)$ and $\mathrm{P}(3)$ indicate the lower bound, upper bound and the standard deviation of the prior distributions. Means of the prior distributions were set to the calibrated values.

The estimation improved in-sample forecasting performance of the model. Properties of the estimated model were analyzed by checking its in-sample fit and comparing it to the fit of the original version of the model. RMSE of the estimated model shows better results for inflation and GDP growth, and almost the same results for the interest and exchange rates (Table 3). 
Table 3. RMSE Comparison of the Main Model Variables

\begin{tabular}{|c|c|c|c|c|c|c|}
\hline Variable & $1 Q$ & $2 Q$ & $3 Q$ & $4 Q$ & $5 Q$ & $6 Q$ \\
\hline \multicolumn{7}{|l|}{ Core Inflation, \% YoY } \\
\hline original & 0.8 & 1.3 & 1.7 & 2.1 & 2.3 & 2.3 \\
\hline estimated & 0.7 & 1.1 & 1.4 & 1.8 & 1.9 & 1.9 \\
\hline \multicolumn{7}{|l|}{ Real GDP, \% YoY } \\
\hline original & 1.2 & 1.7 & 2.0 & 2.2 & 1.8 & 1.7 \\
\hline estimated & 1.0 & 1.3 & 1.4 & 1.5 & 1.6 & 1.7 \\
\hline \multicolumn{7}{|l|}{ Nominal Interest Rate, \% } \\
\hline original & 1.3 & 1.2 & 1.3 & 1.4 & 1.5 & 1.5 \\
\hline estimated & 1.2 & 1.2 & 1.3 & 1.4 & 1.6 & 1.6 \\
\hline \multirow{2}{*}{\multicolumn{7}{|c|}{$\begin{array}{l}\text { Nominal Exchange Rate } \\
\text { Depreciation, \% YoY }\end{array}$}} \\
\hline & & & & & & \\
\hline original & 2.1 & 3.2 & 3.8 & 4.1 & 4.6 & 4.8 \\
\hline estimated & 2.1 & 3.3 & 4.0 & 4.3 & 4.7 & 4.9 \\
\hline
\end{tabular}

\section{ECONOMiC IMPlications AND MOdel Properties}

\section{V.A. Dynamic Properties}

In this section we demonstrate the dynamic properties of the model by analyzing impulse responses to main structural shocks. Impulse response function is an important tool for understanding the dynamic properties, and the monetary transmission channels of the model, thus helping in the calibration of the model. An impulse-response function (IRF) refers to the reaction of the modelled variables in response to an (one percent) unexpected shock in the first period of simulation. The figures are presented relative to the variables' steady state. 
Figure 4. Demand Shock
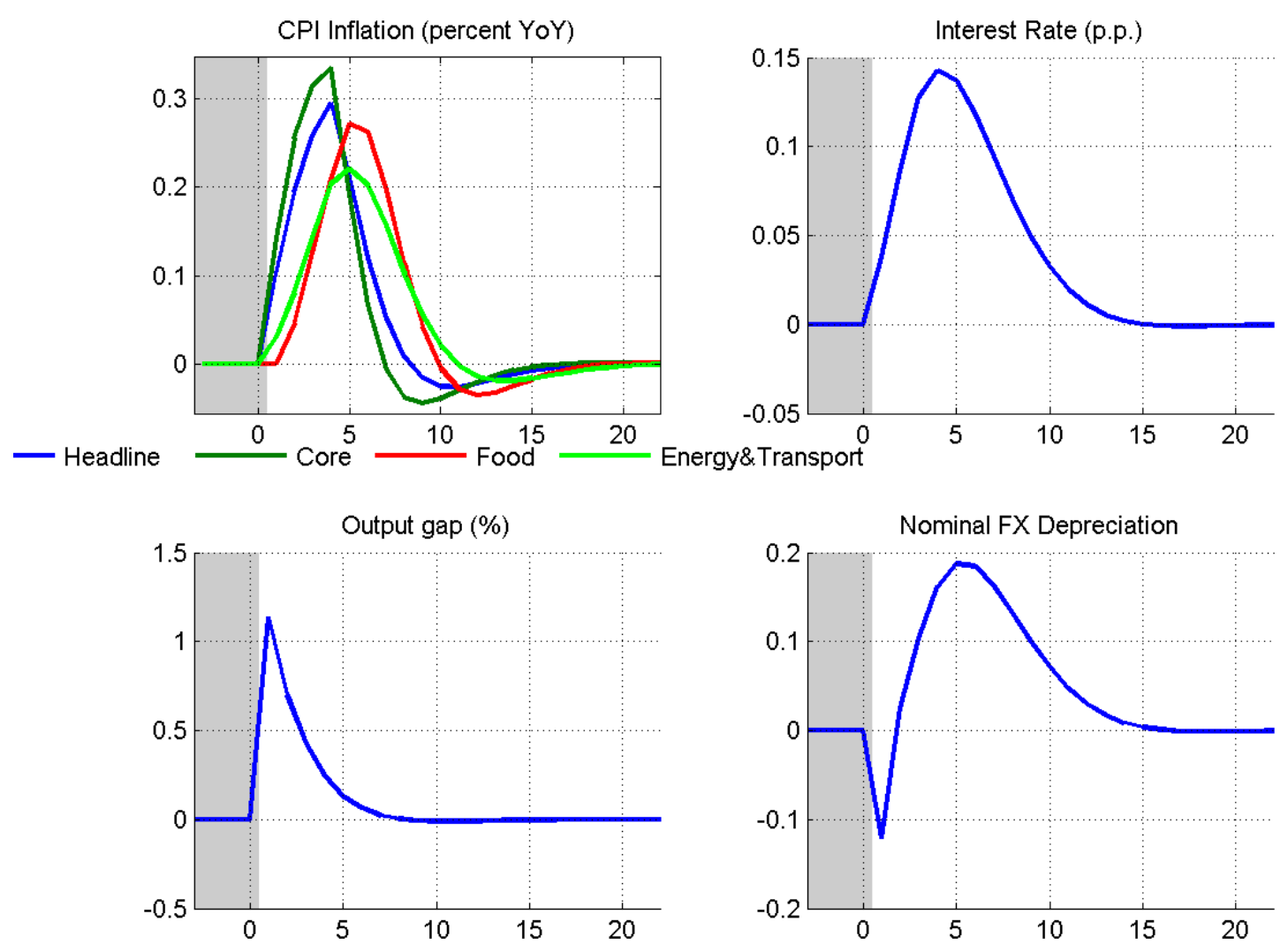

The aggregate domestic demand temporary increases when a positive output shock hits the economy. Since core price dynamics in Sri Lanka are mainly driven by excess demand pressures, we are expecting an immediate increase in the price of core items. This inflation should pass through within the supply chain to other sectors resulting in higher headline inflation. As one of the main objectives of CBSL is to maintain price stability, the authorities need to react by tightening the policy rate to mitigate the demand side inflationary pressure. The uncovered interest rate parity principle implies that the higher interest rate, which makes Sri Lanka more attractive for foreign investors results a temporary appreciation of the nominal exchange rate. The stronger currency coupled with tight policy stance can reduce domestic economic activity, and the vanishing excess demand and lower import prices can bring inflation back to its target. 
Figure 5. Monetary Policy Tightening
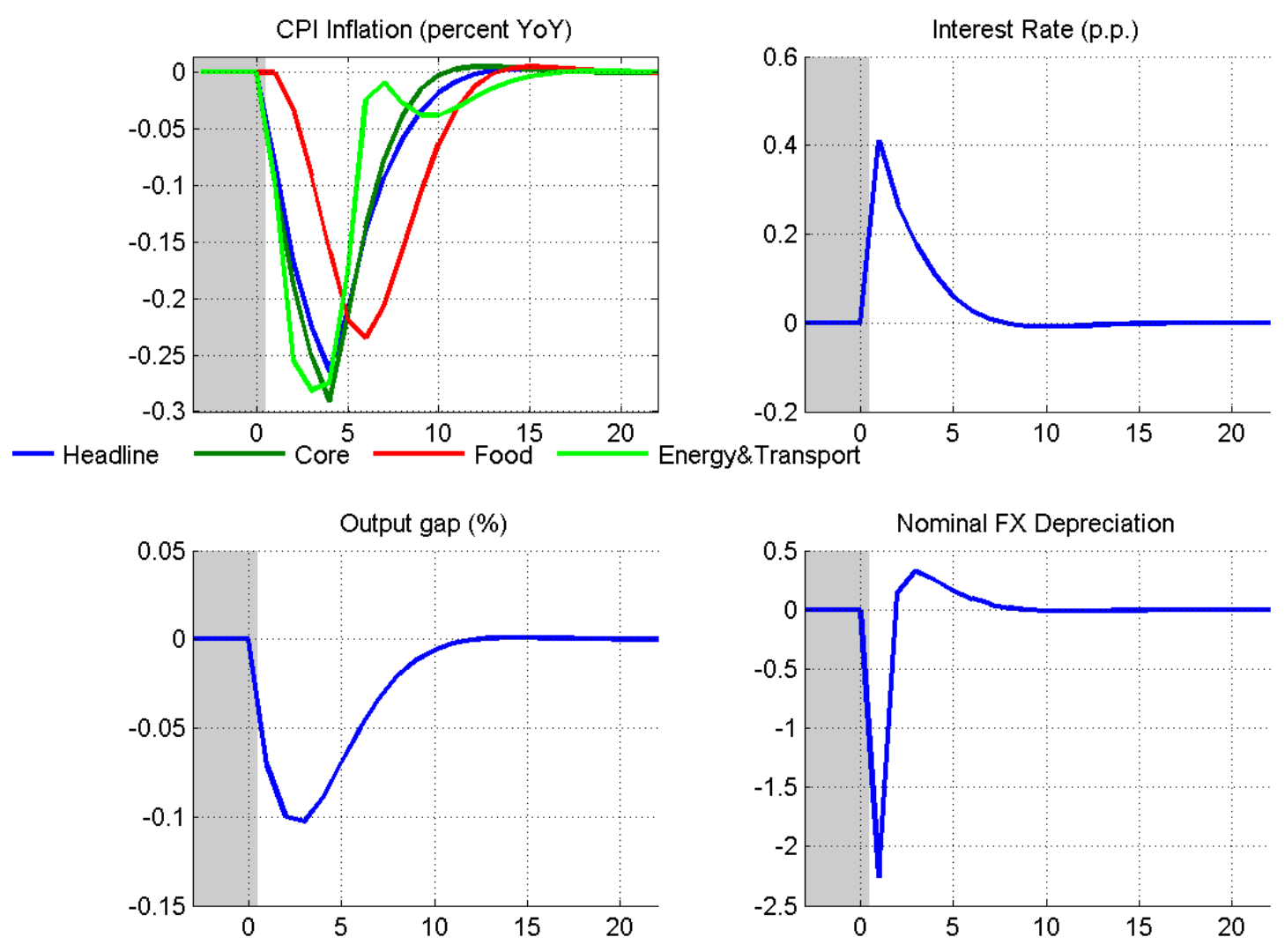

An unexpected increase in the Sri Lankan policy rate makes the country more attractive to invest thus the UIP condition implies an immediate exchange rate appreciation. As the change of policy rate passes through to commercial loan and deposit rates, the increased returns encourage domestic agents to postpone their spending and save more. On the other hand, the overvalued domestic currency makes Sri Lankan export (import) more expensive (cheaper) indicating a temporary contraction of the real activity. The lower imported production costs caused by the strong domestic currency together with economic slowdown (negative output and real exchange rate gap) can reduce demand (core) and exchange rate (Energy \&Transportation) sensitive inflations temporarily. 
Figure 6. Temporary Exchange Rate Shock
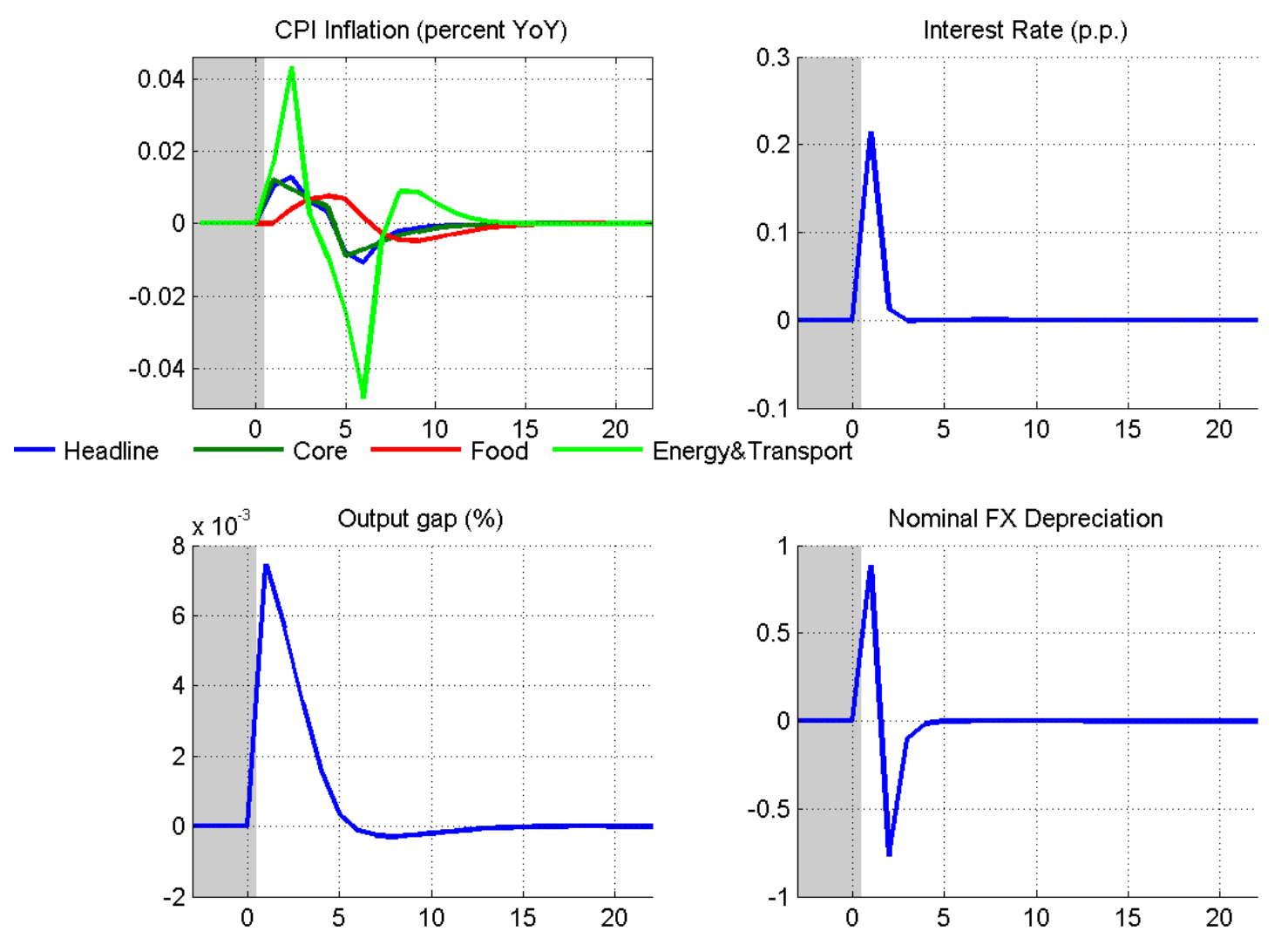

The rupee temporarily depreciates in a response to an unexpected foreign exchange (UIP) shock representing a temporary worsening of foreign investors' appetite for Sri Lankan assets. The weak currency increases the import prices which raise domestic commodity prices (Energy \& Transport and non-volatile food) directly, and also results in a supply side inflationary pressure in the other sectors through the higher production costs. Since Sri Lanka is highly globally integrated the growing competitiveness of traded goods - due to the depreciation of rupee - heats economic activity. This excess demand results in an inflationary pressure. To reach price stability and to bring exchange rate closer to its desired level, the CBSL needs to cool down economic activity and to appreciate domestic currency by setting more restrictive monetary conditions.

Difference in dynamic properties of the inflation components is consistently reflected in the structure of the model. The transmission of the inflationary shocks into economy depends on 
its nature and therefore requires different magnitude and duration of the monetary policy reaction. Volatile food price shocks are usually caused by the temporary factors and fade out relatively fast, while the prices included into core index have more persistent factors behind them and require more attention of the monetary policy. Impulse responses in Figure 7 show reactions of the monetary policy to the 1 percentage point increase in the headline inflation caused by the different inflationary shocks. Current model structure implies the strongest policy reaction in case of the core inflation shock as the impact of this shock on the economy is the highest and most persistent if compared to the other inflationary shocks. In line with its temporary nature, the effect of the volatile food price shock is the smallest and requires relatively modest policy reaction.

Figure 7. Policy Response to the Different Supply Shocks
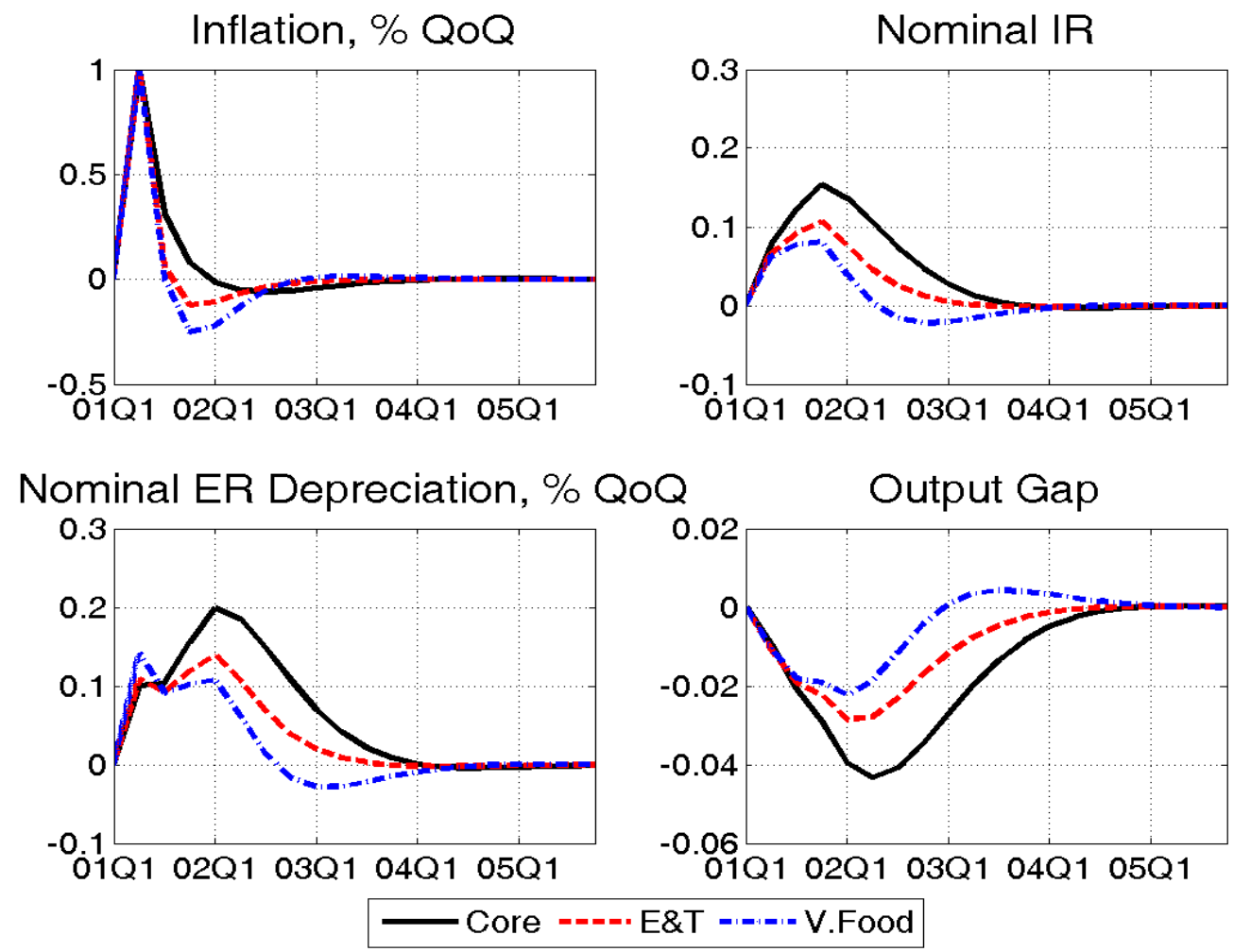

\section{V.B. Historical Shock Decomposition}

Another important tool used in calibration process is analyzing the past shocks identified by the model during the filtration stage to check whether the interpretation of past events is in 
line with expert's views and stylized facts. shows the historical shock decomposition of annual inflation. The graph implies that the model identifies the source of past inflationary pressures properly.

The foreign real economy and the weak exchange rate (captured by positive effect of monetary and exchange rate shocks) contributed to the Sri Lankan inflation positively until the beginning of financial crises, but the main contributors of the high inflation period between 2007 and 2009 were the growing domestic non-core prices. One factor behind these dynamics was the high imported inflation caused by increasing international commodity prices but since domestic administered energy inflation was higher than what underlying factors explained, the model identifies large domestic supply shocks for this period. The imported disinflation due to the big drop in international commodity prices during the years of financial crises resulted in a large domestic disinflation in 2009 which effect was amplified by the negative real effect of the crises, captured by the negative foreign economy shocks. Although increasing commodity prices forced domestic prices to go up from 2010 the stable exchange rate (negative contribution of exchange rate and monetary policy shocks) and the permanently weak foreign demand kept Sri Lankan inflation stable until 2012. As the commodity prices fell again in late 2011 the domestic prices started to decline but the looser monetary stance, and the depreciation of rupee led to a higher inflation. After the stabilization of exchange rate prices started to fall from 2013. Disinflation was amplified by the reduction in domestic and foreign economic activity from 2014 and the low commodity prices from 2015. 
Figure 8. Shock Decomposition of Annual Inflation

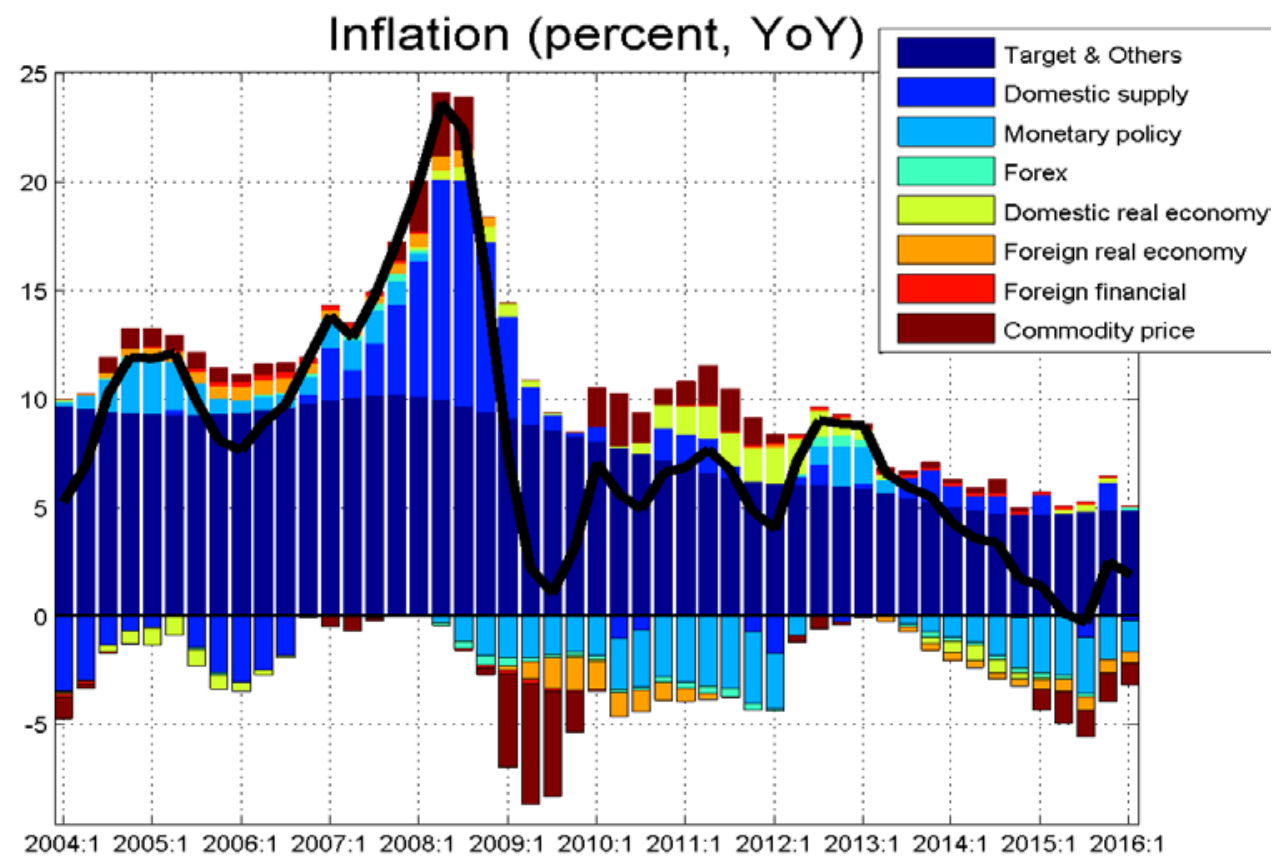

Figure 9. Shock Decomposition of Real Output Gap

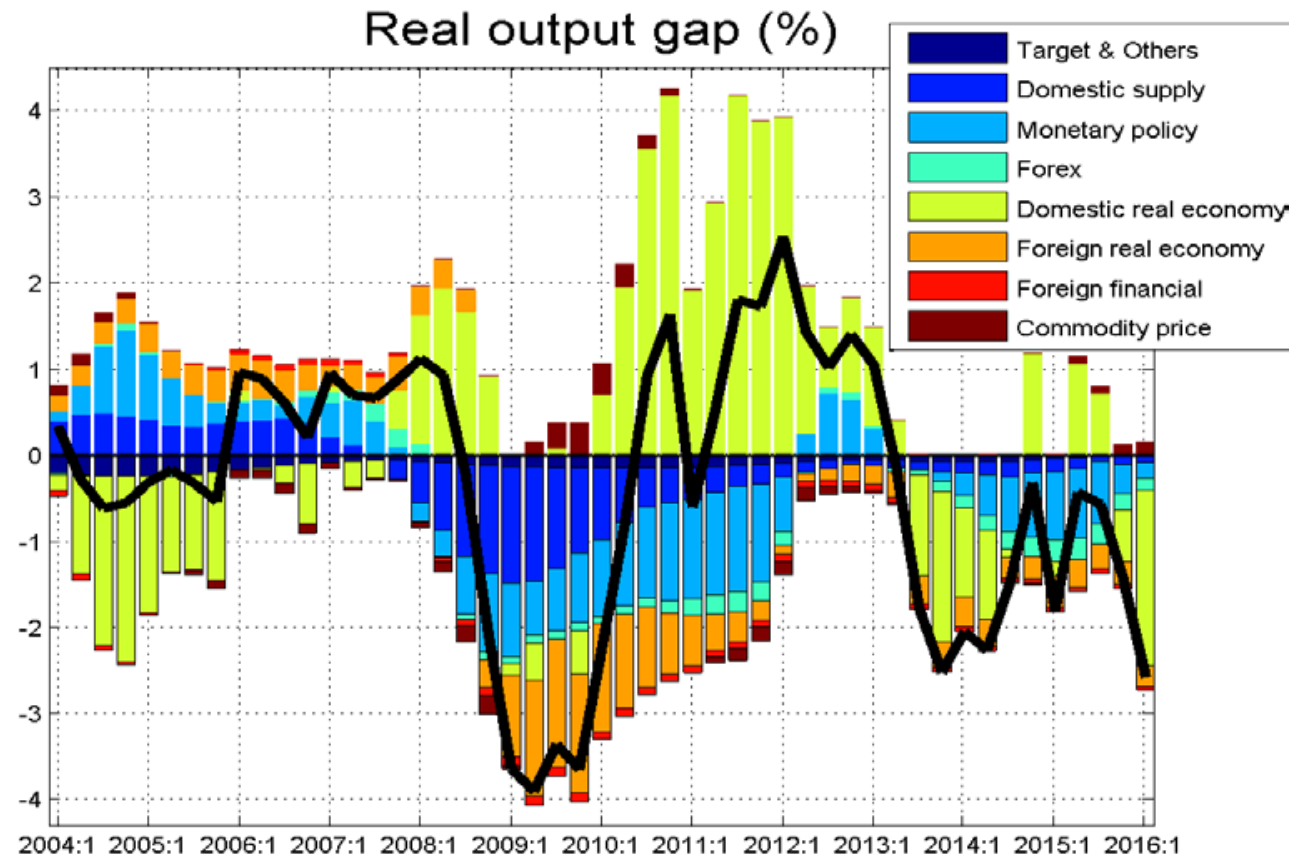


Despite the weak domestic demand, weak currency (captured by the positive effect of monetary policy and foreign exchange shocks) and strong foreign demand kept output gap close to zero in the early 2000's. As domestic demand increased from the mid 2000's and as the exchange rate started to depreciate significantly, Sri Lankan economy became slightly overheated from 2006 until being hit by the global financial crises. The negative effect of declining foreign demand caused by the crisis was amplified by a tight monetary stance resulting in overvaluation of the rupee until its devaluation in 2012. These impacts were muted and offset by an improvement in domestic demand from 2009 when the civil war ended. The tight monetary policy, decreasing domestic and foreign demand have resulted in a permanently opened output gap since 2013.

\section{V.C. Historical Forecast Performance}

The third important tool used in empirical validation process is checking the model's historical in sample forecast performance. In this exercise, we examine whether the model would have given reasonable projections and policy advices in the past. These in-sample simulations for each quarter in range from 2004Q1 to 2015Q4 are conducted as follows:

- all the observed variables are treated as known until the starting date of each simulation;

- external variables which are exogenous to the $\operatorname{model}^{8}$ are treated as known over the forecast horizon (8 quarters ahead), because the QPM is not supposed to produce forecast for those variables.

Figure 10 shows the in-sample forecast of the main macro variables (colored dashed lines) compared with the actual data (solid black line). The figures suggest that the forecasting ability of model is satisfactory: the model forecasts inflation and real growth quite precisely, however there are periods when the model failed to predict the actual outcome.

\footnotetext{
${ }^{8}$ These are: US output gap; Fed funds rate; US CPI; international oil and food prices gap;
} 
Figure 10. In-sample Forecast of the Main Macro Variables
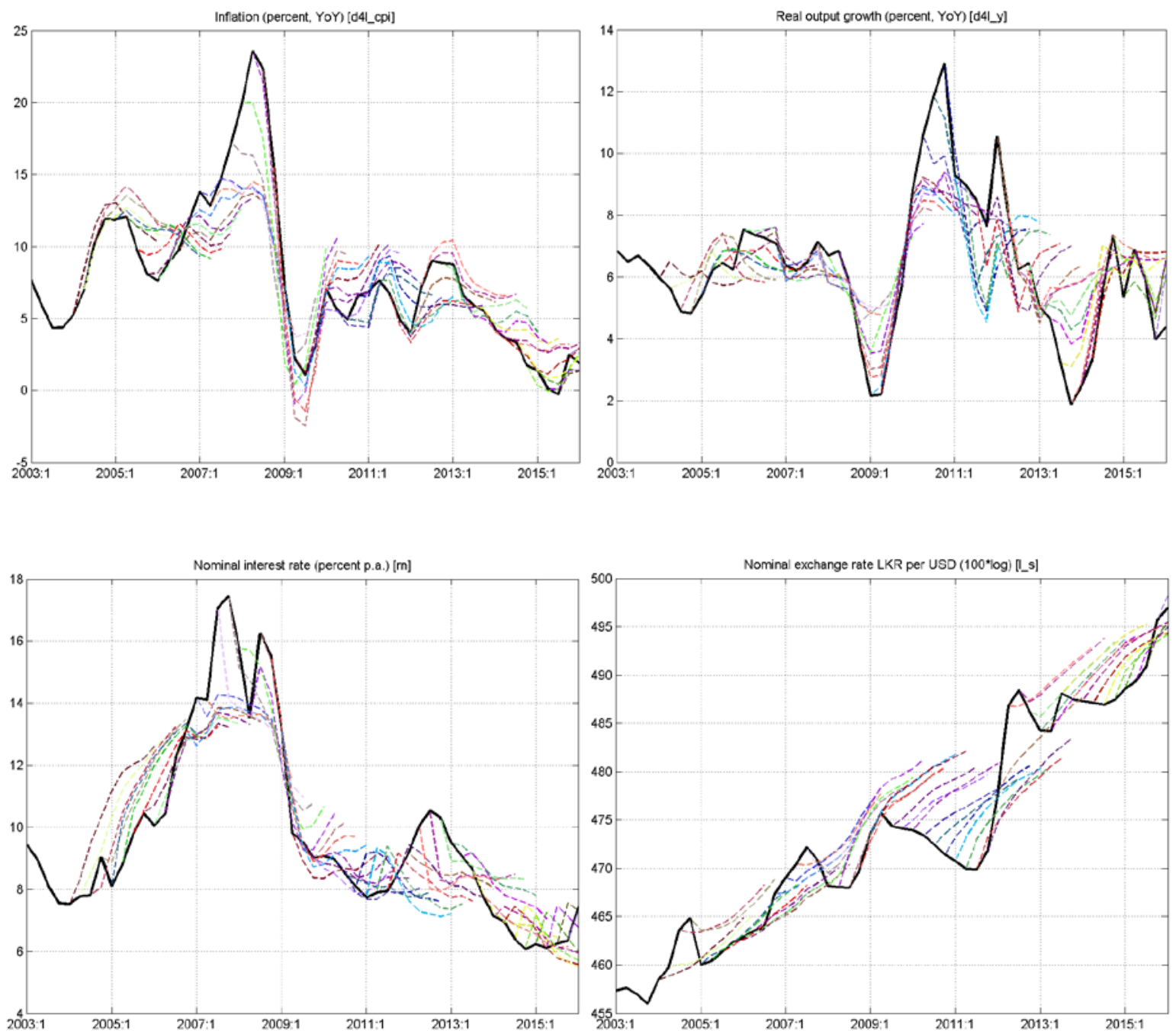

The in-sample simulations for inflation and interest rates deviated substantially from the actual outcome in the high inflationary period from 2007 to the middle of 2008, when domestic commodity prices increased much more than what international price dynamics would have explained. However, the forecast performance of the model improved after the domestic supply shocks died out and foreign shocks (financial crises, low commodity prices in 2009) started to drive the dynamics of Sri Lankan prices. The forecast was a slightly biased for the period $2010-2011$ when the model was unable to predict the significant appreciation of the rupee. 
Similarly, the model performs well in the case of real growth: the forecast errors are small before and during the financial crises but failed to project the large growth rates that were observed after the end of the civil war and the small growth rates when floods afflicted the Sri Lankan economy.

We can conclude that the forecast performance of the model performs is very good in periods when only small shocks or only foreign shocks hit the Sri Lankan economy but underperforming for periods with large, well identifiable and unpredictable domestic shocks. This finding implies that the current calibration of this simple model captures the fundamental relationship of economic variables and the underlying dynamics of the Sri Lankan economy well.

The historical performance is also evaluated by examining the forecast errors. Table 6 reports the ratio of the root mean square errors (RMSE) of the model forecast to that from the random walk (RW) for one to eight quarters ahead. A value smaller than one indicates that our model outperforms the random walk. The smaller the ratio is the better the model predicts the variable than the random walk. The QPM outperforms the random walk model as the computed ratios are less than unity for all variables over the forecast horizon, with an exception of interest rate forecast in one quarter ahead.

Table 6. Ratio of RMSE of the Model Forecast to that from the Random Walk

\begin{tabular}{|l|c|c|c|c|c|c|c|c|}
\hline \multicolumn{1}{|c|}{ Quarters ahead } & $\mathbf{1 Q}$ & $\mathbf{2 Q}$ & $\mathbf{3 Q}$ & $\mathbf{4 Q}$ & $\mathbf{5 Q}$ & $\mathbf{6 Q}$ & $\mathbf{7 Q}$ & $\mathbf{8 Q}$ \\
\hline Real GDP growth (percent, YoY) & 0.69 & 0.60 & 0.52 & 0.47 & 0.46 & 0.48 & 0.50 & 0.54 \\
CCPI Inflation (percent, YoY) & 0.52 & 0.50 & 0.49 & 0.49 & 0.46 & 0.47 & 0.49 & 0.51 \\
LKR per USD FX rate (100*log) & 0.88 & 0.80 & 0.77 & 0.74 & 0.72 & 0.71 & 0.70 & 0.69 \\
Nominal Interest Rate (percent p.a.) & 1.09 & 0.71 & 0.61 & 0.59 & 0.53 & 0.48 & 0.45 & 0.43 \\
\hline
\end{tabular}




\section{Directions For Future ANALYSIS}

The current model needs to be extended further in few other directions to provide a comprehensive policy analysis on Sri Lankan economy. First, it is important to extend the model to capture the effects of fiscal policy that are essential in monetary policy implementation. Large and persistent fiscal deficit in Sri Lanka is an important factor to be considered. Adding a fiscal block to the model will capture the effect of government spending, including countercyclical fiscal policy, as well as changes made to the tax structure on output and inflation. In addition, as well as the effect of government borrowings on equilibrium interest rates and the external balance will also be taken into consideration.

Secondly, the model can also be extended to capture the financial sector in order to incorporate the effect of financial distortions on interest rates and investments, highlighting the importance of macro-financial linkages. Since the onset of the financial crisis, the link between financial markets and real economic activity has become increasingly important. In the Sri Lankan context, the CBSL focuses on both price stability and financial system stability as its key objectives under the current Monetary Law Act. At present, financial stability assessment and its macroeconomic implications are monitored and assessed outside of the core model. However, going forward the financial sector assessment is expected to be incorporated within the FPAS, in order to produce projections that are conditional on the status of financial sector stability. Therefore, adding financial frictions would be essential in order to incorporate the effect of financial distortions on interest rates and investments. Literature offers different micro-foundations of financial frictions. This includes the influential work of Bernanke et al. (1999) on credit market imperfections under the financial accelerator model. In addition, Gertler and Kiyotaki (2010) and Gertler and Karadi (2011) extend the standard DSGE model considering the banking sector as a source of financial frictions due to the moral hazard problem. As a first step towards incorporating financial sector linkages, a monetary block is proposed to be added to the core QPM. This extension will capture the implications of growing money to GDP and credit to GDP ratios and frequent occurrence of credit cycles in the recent years. Also, this will suit the current enhanced monetary policy framework in Sri Lanka, that still incorporates the features of both monetary targeting and inflation targeting. 
Due to the limited information and data available on Sri Lankan economy, values of the model parameters in this study are mostly based on judgment. In future, once necessary data are available, model parameters could be estimated using Sri Lankan data to incorporate micro foundations and to improve the model performance.

\section{CONCLUSION}

This paper outlines a model based systematic approach developed under FPAS for conducting monetary policy analysis at the CBSL. QPM, which is the key element of this system, is a semi-structural open economy macroeconomic model based on the principles of DSGE modelling. QPM allows forecasting of key macroeconomic variables with the facility to conduct simulation of alternative policy options. While QPM will be the main macroeconomic model of CBSL, various nowcasting and near-term forecasting tools that CBSL has been using for some time would continue with a number of new models for nearterm projections to provide useful insights to the QPM projections.

The paper presents the economic rationale and theoretical and practical aspects underpinning the development of the QPM together with the means of calibration and fine-tuning the model. Further, model simulations are presented to illustrate how policy making institutions might respond to various types of shocks with a view to achieving macroeconomic stability, in particular, to bring inflation back to the announced target over the medium-term. The paper also provides information on the historical decomposition of the causal factors to the evolution of some of the key macroeconomic variables.

As the Sri Lankan economy has undergone a significant economic transformation, a coherent macroeconomic model like QPM coupled with the systematic decision-making process introduced through FPAS would facilitate proactive monetary policy making in a more forward-looking manner. Particularly, with the transition of the conduct of monetary policy from a monetary targeting framework to a flexible inflation targeting framework, FPAS is expected to serve as an indispensable tool in the overall monetary policy decision making process of CBSL. 


\section{REFERENCES}

Alichi, A., Benes, J., Felman, J., Feng, I., Freedman, C., Laxton, D., Tanner, E., Vavra, D., Wang, H., "Frontiers of Monetary Policymaking: Adding the Exchange Rate as a Tool to Combat Deflationary Risks in the Czech Republic", IMF Working Paper 15/74, 2015

Andrle, M., Berg, A., Morales, R.A., Portillo, R. and Vlcek, J., "Forecasting and Monetary Policy Analysis in Low-Income Countries: Food and non-Food Inflation in Kenya", IMF Working Paper 13/61, 2013.

Amarasekara, C., "Interest Rate Pass-through in Sri Lanka", Staff Studies, Vol. 35, Nos 1 and 2, Central Bank of Sri Lanka, 2005.

Amarasekara, C., "The Impact of Monetary Policy on Economic Growth and Inflation in Sri Lanka”. Staff Studies. 38(1), pp.1-44. 2008.

An, S., Schorfheide, F., "Bayesian Analysis of DSGE Models", Econometric Reviews, 26:24, p.113-172, 2007.

Anand, R., Ding, D., Peiris, S.J., “Toward Inflation Targeting in Sri Lanka”, 2011.

Benes, J., Clinton, K., George, A., John, J., Kamenik, O., Laxton, D., Mitra, P., Nadhanael, G., Wang, H., Zhang, F., "Inflation-Forecast Targeting for India: An Outline of the Analytical Framework”, Reserve Bank of India, Working Paper 07/2016, 2016.

Benes, J., Clinton, K., George, A., Gupta, P., John, J., Kamenik, O., Laxton, D., Mitra, P., Nadhanael, G., Portillo, R., Wang, H., Zhang, F., "Quarterly Projection Model for India: Key Elements and Properties”, Reserve Bank of India, Working Paper 08/2016, 2016.

Berg, A., Karam, P. and Laxton D., "Practical Model-Based Monetary Policy Analysis: A How-to Guide", IMF Working Paper 06/081, 2006.

Bernanke, B.S., and Bovin, J., "Monetary Policy in a data-rich environment", Journal of Monetary Economics, 2003.

Bernanke, B.S., Gertler, M., and Gilchrist, S., "The financial accelerator in a quantitative business cycle framework", Handbook of Macroeconomics, Elsevier, Volume 1, Part C, Pages 1341-1393, 1999.

Ehelepola, K. "An Estimated Open Economy New Keynesian DSGE Model for Sri Lanka with Monetary and Fiscal Rules". Conference proceedings, 8 th International Research conference, Central Bank of Sri Lanka. 2015.

Ehelepola, K. "Optimal Monetary and Fiscal Policy Analysis for Sri Lanka; A DSGE Approach". Conference proceedings, $7^{\text {th }}$ International Research conference, Central Bank of Sri Lanka. 2014. 
Faust, J., and Wright, H., "Comparing green book and reduced form forecasts using s large real time dataset”, Journal of Business and Economic Statistics, 2009.

Fukuda, K., "Forecasting real-time data allowing for data revisions", Journal of Forecasting, 2007.

Gertler, M., and Karadi, P., "A model of unconventional monetary policy," Journal of Monetary Economics, Elsevier, vol. 58(1), pages 17-34, 2011.

Gertler, M., and Kiyotaki, N., "Financial Intermediation and Credit Policy in Business Cycle Analysis", Handbook of Monetary Economics, Volume 3, Pages 547-599, 2010. Edited by Benjamin M. Friedman and Michael Woodford

Ghosh, S., and Lien, D., "Forecasting with preliminary data: a comparison of two methods", Journal of Applied Economics, 2001.

Howrey, E.,P., "The use of preliminary data in econometric forecasting", Review of Economics and Statistics, 1978.

International Monetary Fund "Conditionality in Evolving Monetary Policy Regimes", IMF Policy paper, 2014.

International Monetary Fund "Evolving Monetary Policy Frameworks in Low-Income and Other Developing Countries”, Staff Report, 2015.

Jayamaha, R., Thenuwara, H.N., Weerasinghe, P.N., Silva, B.D.W.A., Karunathilake, C.P.A., Rathnasiri, H.P.G.S., Chandrawansa, P.H.O., Perera, R.A., and Gunaratne, S. "Feasibility of Inflation Targeting in Sri Lanka", Staff Studies, Vol. 31-32, Central Bank of Sri Lanka, 2002.

Jayawickrema, V.S. and Perera, R.A., "Monetary Policy Rules in Practice: Evidence from Sri Lanka. $6^{\text {th }}$ Central Bank of Sri Lanka International Research Conference. 2013.

Jegajeevan, S. "What Drives Sri Lankan Business Cycles? A DSGE Model Based Approach", Central Bank of Sri Lanka , 2014.

Karunaratne, N. D. and Pathberiya, L. R. C. "A Bayesian New Keynesian Small Open Economy Dynamic Stochastic General Equilibrium Model of the Sri Lankan Economy". Conference proceedings, $7^{\text {th }}$ International Research Conference, Central Bank of Sri Lanka. 2014.

Karunasena, A.G., “A Macroeconometric Model for Sri Lanka”, Central Bank of Sri Lanka, 1986.

Laxton, D., Scott, A., Rose, D., "Developing a Structured Forecasting and Policy Analysis System to Support Inflation-Forecast Targeting (IFT)", IMF Working Paper 09/65, 2009. 
Lubik, T., Schorfheide, F., "A Bayesian Look at the New Open Economy Macroeconomics", NBER Macroeconomics Annual 2005, Volume 20, p.313-382, MIT Press, April 2006.

Mahadeva, L. and Thenuwara, H N, "Scope for Inflation Targeting in Sri Lanka - Focus on Money Market Efficiency and Administered Prices”, Staff Studies, Vol. 29-30, Central Bank of Sri Lanka, 2000.

Mankiw, N.G., and Shapiro, M. D., "News or Noise: an analysis of GNP revisions", Survey of Current Business (66), 1986.

Mohanty, M. S. and Klau, M., Monetary policy rules in emerging market economies: issues and evidence, BIS Working Papers 149, 2004.

Perera, R.A.A., "Core Inflation in Sri Lanka: Is it a Useful Guiding Indicator in Conducting Monetary Policy", Presented at the Central Bank of Sri Lanka $-2^{\text {nd }}$ International Research Conference, 2009.

Perera, R.A.A., "Is Sri Lanka Ready for Inflation Targeting?" Papers Presented at the Central Bank of Sri Lanka Inaugural International Research Conference, 2008.

Ratnasiri, H.P.G.S., "The Main Determinants of Inflation in Sri Lanka: A VAR based Analysis". Staff Studies. 39(1), pp.1-14. 2011.

Schmitt-Grohé, S., Uribe, M., "Optimal simple and implementable monetary and fiscal rules", Journal of Monetary Economics, Volume 54, Issue 6, 2007.

Sirisena, N.L., “A Multisectoral Production Model for Sri Lanka”, Central Bank of Ceylon, 1976.

Thenuwara, H N, "The Scope for Inflation Targeting in Sri Lanka - A focus on the Transmission Mechanism", Staff Studies, Vol. 27-28, Central Bank of Sri Lanka, 1998.

Weerasinghe P.N., Silva, B.D.W.A., Ratnasiri H.P G S, Wimalasuriya S M, and Yatigammana T M R P, "Guide to Forecasting with Autoregressive Models: Based on the Workshop on VAR Modelling at Sveriges Riksbank”, (Unpublished) 2005.

Wijesinghe, D.S., "Some Experiments with a Multisectoral Intertemporal Optimisation Model for Sri Lanka", 1986.

Wijewardena, W.A., "Central Banking Nearly Six Decades after John Exter", 19th Anniversary Convention, Association of Professional Bankers, Sri Lanka, 2007.

Wimalasuriya, S.M., "Exchange Rate Pass-Through: To What Extent Do Prices Change in Sri Lanka?” Staff Studies. 37(1), pp.49-67. 2009. 


\section{ApPendiX A. COMPlete MOdel}

$$
\begin{aligned}
& \text { Model Equations } \\
& \hat{y}_{t}=a_{1} \cdot \hat{y}_{t-1}+a_{2} \cdot \hat{y}_{t+1}-a_{3} \cdot \hat{r}_{t}+a_{4} \cdot \hat{y}_{t}^{\text {foreign }}-a_{5} \cdot \hat{z}_{t}+\varepsilon_{t}^{\hat{y}} \\
& i_{t}^{\text {pol }}=a_{7} \cdot i_{t-1}+\left(1-a_{7}\right) \cdot\left(i_{t}^{\text {neu }}+a_{8} \cdot \hat{\pi}_{t}+a_{9} \cdot \hat{y}_{t}\right)+\varepsilon_{t}^{i} \\
& i_{t}^{\text {pol }}=i_{t}^{\text {foreign }}+4 \cdot\left({ }^{e} s_{t}-s_{t}^{\text {uip }}\right)+\rho_{t}+\varepsilon_{t}^{\Delta s} \\
& \Delta s_{t}^{p o l}=a_{10} \cdot \Delta s_{t-1}^{p o l}+\left(1-a_{10}\right) \cdot\left(-\Delta \bar{z}_{t}+\bar{\pi}_{t}-\pi_{s s}^{\text {foreign }}+a_{11} \cdot \hat{z}_{t-1}\right)+\varepsilon_{t}^{\Delta s^{p o l}} \\
& \Delta s_{t}^{p o l}=4 \cdot\left(s_{t}^{p o l}-s_{t-1}\right) \\
& \Delta s_{t}^{\text {uip }}=4 \cdot\left(s_{t}^{\text {uip }}-s_{t-1}\right) \\
& i_{t}^{\text {uip }}=i_{t}^{\text {foreign }}+4 \cdot\left({ }^{e} s_{t}-s_{t}^{p o l}\right)+\rho_{t}+\varepsilon_{t}^{\Delta s} \\
& i_{t}=a_{12} \cdot i_{t}^{p o l}+\left(1-a_{12}\right) \cdot i_{t}^{u i p} \\
& s_{t}=a_{12} \cdot s_{t}^{u i p}+\left(1-a_{12}\right) \cdot s_{t}^{p o l} \\
& \hat{\pi}_{t}=\pi_{t+4}-\bar{\pi}_{t} \\
& i_{t}^{n e u}=\bar{r}_{t}+\pi_{t+1}^{4} \\
& r_{t}=i_{t}-\pi_{t+1}^{4} \\
& r_{t}=\hat{r}_{t}+\bar{r}_{t} \\
& \pi_{t}=a_{14} \cdot \pi_{t}^{c}+a_{13} \cdot \pi_{t}^{v f}+\left(1-a_{14}-a_{13}\right) \cdot \pi_{t}^{e t}+\pi_{t}^{\text {disc }} \\
& \pi_{t}^{\text {disc }}=a_{26} \cdot \pi_{t-1}^{d i s c}+\varepsilon_{t}^{\pi^{d i s c}} \\
& \pi_{t}^{c}=a_{15} \cdot \hat{y}_{t}+a_{16} \cdot \pi_{t-1}^{c}+\left(1-a_{16}-a_{19}\right) \cdot \pi_{t+1}^{c}-a_{17} \cdot\left(\hat{z}_{t}-a_{13} \cdot \hat{r p}_{t}^{v f / c}-(1\right. \\
& \left.\left.-a_{13}-a_{14}\right) \cdot \hat{r p}_{t}^{e t / c}\right)+a_{18} \cdot \hat{r p}_{t}^{e t / c}+a_{19} \cdot \Delta p_{t}^{f o o d, i m p, c}+\varepsilon_{t}^{\pi^{c}} \\
& \pi_{t}^{v f}=a_{20} \cdot \pi_{t-1}^{v f}+\left(1-a_{20}\right) \cdot \bar{\pi}_{t}^{v f}-a_{21} \cdot \hat{r p}_{t-1}^{v f / c}+\varepsilon_{t}^{\pi^{v f}} \\
& \pi_{t}^{e t}=a_{22} \cdot \pi_{t-1}^{e t}+\left(1-a_{22}-a_{23}\right) \cdot \pi_{t+1}^{e t}+a_{23} \cdot \Delta p_{t-1}^{\text {oil,imp,et }}+a_{24} \cdot \hat{q}_{t-1}^{\text {oil,et }}-a_{25} \\
& \cdot \hat{r p}_{t-1}^{e t / c}+\varepsilon_{t}^{\pi^{e t}} \\
& r p_{t}^{v f / c}=p_{t}^{v f}-p_{t}^{c} \\
& r p_{t}^{v f / c}=\overline{r p}_{t}^{v f / c}+\hat{r p}_{t}^{v f / c} \\
& \Delta \overline{r p}_{t}^{v f / c}=4 \cdot\left(\overline{r p}_{t}^{v f / c}-\overline{r p}_{t-1}^{v f / c}\right) \\
& \Delta^{4} \overline{r p}_{t}^{v f / c}=\overline{r p}_{t}^{v f / c}-\overline{r p}_{t-4}^{v f / c} \\
& \Delta \overline{r p}_{t}^{v f / c}=a_{27} \cdot \Delta \overline{r p}_{t-1}^{v f / c}+\left(1-a_{27}\right) \cdot \Delta \overline{r p}_{s s}^{v f}+\varepsilon_{t}^{\Delta \overline{r p}^{v f / c}} \\
& r p_{t}^{e t / c}=p_{t}^{e t}-p_{t}^{c} \\
& r p_{t}^{e t / c}=\overline{r p}_{t}^{e t / c}+\hat{r p}_{t}^{e t / c} \\
& \Delta \overline{r p}_{t}^{e t / c}=4 \cdot\left(\overline{r p}_{t}^{e t / c}-\overline{r p}_{t-1}^{e t / c}\right)
\end{aligned}
$$




$$
\begin{aligned}
& \Delta^{4} \overline{r p}_{t}^{e t / c}=\overline{r p}_{t}^{e t / c}-\overline{r p}_{t-4}^{e t / c} \\
& \Delta \overline{r p}_{t}^{e t / c}=a_{28} \cdot \Delta \overline{r p}_{t-1}^{e t / c}+\left(1-a_{28}\right) \cdot \Delta \overline{r p}_{s s}^{e t}+\varepsilon_{t}^{\Delta \overline{r p}^{e t / c}} \\
& \bar{r}_{t}=\bar{r}_{t}^{\text {foreign }}-\Delta \bar{z}_{t+1}+\rho_{t} \\
& \Delta \bar{y}_{t}=a_{6} \cdot \Delta \bar{y}_{t-1}+\left(1-a_{6}\right) \cdot \Delta \bar{y}_{s s}+\varepsilon_{t}^{\Delta \bar{y}} \\
& \Delta \bar{z}_{t}=a_{30} \cdot \Delta \bar{z}_{t-1}+\left(1-a_{30}\right) \cdot \Delta \bar{z}_{s s}+\varepsilon_{t}^{\Delta \bar{z}} \\
& \rho_{t}=a_{32} \cdot \rho_{t-1}+\left(1-a_{32}\right) \cdot \rho_{s s}+\varepsilon_{t}^{\rho} \\
& \bar{\pi}_{t}=a_{29} \cdot \bar{\pi}_{t-1}+\left(1-a_{29}\right) \cdot \bar{\pi}_{s S}+\varepsilon_{t}^{\bar{\pi}} \\
& y_{t}=\hat{y}_{t}+\bar{y}_{t} \\
& \Delta \bar{y}_{t}=4 \cdot\left(\bar{y}_{t}-\bar{y}_{t-1}\right) \\
& \Delta^{4} \bar{y}_{t}=\bar{y}_{t}-\bar{y}_{t-4} \\
& \Delta y_{t}=4 \cdot\left(y_{t}-y_{t-1}\right) \\
& \Delta^{4} y_{t}=y_{t}-y_{t-4} \\
& e \hat{y}_{t}=\hat{y}_{t+1} \\
& \pi_{t}=4 \cdot\left(p_{t}-p_{t-1}\right) \\
& \pi_{t}^{4}=p_{t}-p_{t-4} \\
& \pi_{t}^{c}=4 \cdot\left(p_{t}^{c}-p_{t-1}^{c}\right) \\
& \pi_{t}^{c, 4}=p_{t}^{c}-p_{t-4}^{c} \\
& \pi_{t}^{v f}=4 \cdot\left(p_{t}^{v f}-p_{t-1}^{v f}\right) \\
& \pi_{t}^{v f, 4}=p_{t}^{v f}-p_{t-4}^{v f} \\
& \pi_{t}^{e t}=4 \cdot\left(p_{t}^{e t}-p_{t-1}^{e t}\right) \\
& \pi_{t}^{e t, 4}=p_{t}^{e t}-p_{t-4}^{e t} \\
& { }^{e} \pi_{t}=\pi_{t+1} \\
& { }^{e} \pi_{t}^{c}=\pi_{t+1}^{c} \\
& { }^{e} \pi_{t}^{v f}=\pi_{t+1}^{v f} \\
& { }^{e} \pi_{t}^{e t}=\pi_{t+1}^{e t} \\
& \bar{\pi}_{t}^{v f}=\bar{\pi}_{t}+\left(1-a_{13}\right) \cdot \Delta \overline{r p}_{t}^{v f / c}-\left(1-a_{14}-a_{13}\right) \cdot \Delta \overline{r p}_{t}^{e t / c} \\
& \bar{\pi}_{t}^{e t}=\bar{\pi}_{t}+\left(a_{14}+a_{13}\right) \cdot \Delta \overline{r p}_{t}^{e t / c}-a_{13} \cdot \Delta \overline{r p} \bar{t}_{t}^{v f / c} \\
& z_{t}=p_{t}-s_{t}-p_{t}^{\text {foreign }} \\
& z_{t}=\hat{z}_{t}+\bar{z}_{t} \\
& \Delta s_{t}=4 \cdot\left(s_{t}-s_{t-1}\right) \\
& \Delta^{4} s_{t}=s_{t}-s_{t-4} \\
& \Delta z_{t}=4 \cdot\left(z_{t}-z_{t-1}\right)
\end{aligned}
$$




$$
\begin{aligned}
& \Delta \bar{z}_{t}=4 \cdot\left(\bar{z}_{t}-\bar{z}_{t-1}\right) \\
& { }^{e} s_{t}=a_{31} \cdot s_{t+1}+\left(1-a_{31}\right) \cdot\left(s_{t-1}+2 \cdot\left(-\Delta \bar{z}_{t}+\bar{\pi}_{t}-\pi_{s s}^{\text {foreign }}\right) / 4\right) \\
& \hat{y}_{t}^{\text {foreign }}=a_{33} \cdot \hat{y}_{t-1}^{\text {foreign }}+\varepsilon_{t}^{\hat{y}^{\text {foreign }}} \\
& r_{t}^{\text {foreign }}=i_{t}^{\text {foreign }}-\pi_{t+1}^{\text {foreign }} \\
& i_{t}^{\text {foreign }}=a_{34} \cdot i_{t-1}^{\text {foreign }}+\left(1-a_{34}\right) \cdot\left(\bar{r}_{t}^{\text {foreign }}+\pi_{s s}^{\text {foreign }}\right)+\varepsilon_{t}^{i^{\text {foreign }}} \\
& \bar{r}_{t}^{\text {foreign }}=a_{35} \cdot \bar{r}_{t-1}^{\text {foreign }}+\left(1-a_{35}\right) \cdot \bar{r}_{s s}^{\text {foreign }}+\varepsilon_{t}^{\bar{r}^{\text {foreign }}} \\
& \pi_{t}^{\text {foreign }}=a_{36} \cdot \pi_{t-1}^{\text {foreign }}+\left(1-a_{36}\right) \cdot \pi_{s s}^{\text {foreign }}+\varepsilon_{t}^{\pi^{\text {foreign }}} \\
& \pi_{t}^{\text {foreign }}=4 \cdot\left(p_{t}^{\text {foreign }}-p_{t-1}^{\text {foreign }}\right) \\
& q_{t}^{\text {oil }}=p_{t}^{\text {oil }}-p_{t}^{\text {foreign }} \\
& q_{t}^{o i l}=\bar{q}_{t}^{\text {oil }}+\hat{q}_{t}^{\text {oil }} \\
& \hat{q}_{t}^{\text {oil }}=a_{38} \cdot \hat{q}_{t-1}^{\text {oil }}+\varepsilon_{t}^{\hat{q}^{\text {oil }}} \\
& \Delta \bar{q}_{t}^{\text {oil }}=a_{39} \cdot \Delta \bar{q}_{t-1}^{\text {oil }}+\left(1-a_{39}\right) \cdot a_{37}+\varepsilon_{t}^{\Delta \bar{q}^{o i l}} \\
& \Delta \bar{q}_{t}^{\text {oil }}=4 \cdot\left(\bar{q}_{t}^{\text {oil }}-\bar{q}_{t-1}^{\text {oil }}\right) \\
& \Delta p_{t}^{\text {oil }}=4 \cdot\left(p_{t}^{\text {oil }}-p_{t-1}^{\text {oil }}\right) \\
& \Delta p_{t}^{\text {oil,imp,et }}=\Delta p_{t}^{\text {oil }}+\Delta s_{t}-\Delta \bar{q}_{t}^{\text {oil }}+\Delta \bar{z}_{t}-\bar{\pi}_{t}+\bar{\pi}_{t}^{e t} \\
& \hat{q}_{t}^{\text {oil,et }}=\hat{q}_{t}^{\text {oil }}-\hat{z}_{t}+a_{13} \cdot \hat{r p}_{t}^{v f / c}-\left(a_{13}+a_{14}\right) \cdot \hat{r p}_{t}^{e t / c} \\
& q_{t}^{\text {food }}=p_{t}^{\text {food }}-p_{t}^{\text {foreign }} \\
& q_{t}^{\text {food }}=\bar{q}_{t}^{\text {food }}+\hat{q}_{t}^{\text {food }} \\
& \hat{q}_{t}^{\text {food }}=a_{41} \cdot \hat{q}_{t-1}^{\text {food }}+\varepsilon_{t}^{\hat{q}^{\text {food }}} \\
& \Delta \bar{q}_{t}^{\text {food }}=a_{42} \cdot \Delta \bar{q}_{t-1}^{\text {food }}+\left(1-a_{42}\right) \cdot a_{40}+\varepsilon_{t}^{\Delta \bar{q}^{\text {food }}} \\
& \Delta \bar{q}_{t}^{\text {food }}=4 \cdot\left(\bar{q}_{t}^{\text {food }}-\bar{q}_{t-1}^{\text {food }}\right) \\
& \Delta p_{t}^{\text {food }}=4 \cdot\left(p_{t}^{\text {food }}-p_{t-1}^{\text {food }}\right) \\
& \Delta p_{t}^{\text {food,imp,c }}=\Delta p_{t}^{\text {food }}+\Delta s_{t}-\Delta \bar{q}_{t}^{\text {food }}+\Delta \bar{z}_{t}-a_{13} \cdot \Delta \overline{r p}_{t}^{v f / c}-\left(1-a_{13}-a_{14}\right) \\
& \cdot \Delta \overline{r p}_{t}^{e t / c}
\end{aligned}
$$


Table 4. Model Variables

\section{Variable Model name}

$y$ I_y

$\Delta y \quad$ dl_y

$\Delta^{4} y \quad$ d4I_y

$\hat{y} \quad$ I_y_gap

$\bar{y} \quad$ I_y_tnd

$\Delta \bar{y} \quad$ dl_y_tnd

$\Delta^{4} \bar{y} \quad$ d4l_y_tnd

$e \hat{y} \quad$ e_l_y_gap

$i \quad \mathrm{rn}$

$i^{\text {neu }} \quad$ rn_neutral

$\bar{r} \quad$ rr_tnd

$\hat{r} \quad$ rr_gap

$r \quad r r$

$i^{\text {pol }} \quad$ rn_pol

$i^{\text {uip }} \quad$ rn_uip

$\pi \quad$ dl_cpi

$\pi^{4} \quad$ d4l_cpi

$p \quad$ I_cpi

$\pi^{c} \quad$ dl_cpi_core

$\pi^{c, 4}$ d4I_cpi_core

$p^{c} \quad$ I_cpi_core

$\pi^{v f} \quad$ dl_cpi_vfood

$\pi^{v f, 4 \quad \text { d4l_cpi_vfood }}$

$p^{v f \quad \text { I_cpi_vfood }}$

$\pi^{e t} \quad$ dl_cpi_et

$\pi^{e t, 4}$ d4l_cpi_et

$p^{e t} \quad$ I_cpi_et

${ }^{e} \pi \quad$ e_dl_cpi

${ }^{e} \pi^{c} \quad$ e_dl_cpi_core

\section{Description}

Real output (100*log)

Real output growth (percent, QoQ annualized)

Real output growth (percent, YoY)

Real output gap (\%)

Real potential output (100*log)

Real potential growth (percent, QoQ annualized)

Real potential growth (percent, YoY)

Expected output gap (percent)

Nominal interest rate (percent p.a.)

Policy neutral rate (percent p.a.)

Eq. real interest rate (percent p.a.)

Real interest rate gap (p.p.)

Real interest rate (percent p.a.)

Inflation targeting nominal interest rate (percent p.a.)

Exchange rate smoothing nominal interest rate (percent p.a.)

Inflation (percent, QoQ annualized)

Inflation (percent, YoY)

CPI $(100 * \log )$

Core Inflation (percent, QoQ annualized)

Core Inflation (percent, YoY)

Core CPI $(100 * \log )$

Volatile Food Inflation (percent, QoQ annualized)

Volatile Food Inflation (percent, YoY)

Volatile Food CPI (100* log)

Energy \& Transport Inflation (percent, QoQ annualized)

Energy \& Transport Inflation (percent, YoY)

Energy \& Transport CPI (100*log)

Expected inflation (percent, QoQ annualized)

Expected core inflation (percent, QoQ annualized) 


\begin{tabular}{|c|c|c|}
\hline Variable & Model name & Description \\
\hline${ }^{e} \pi^{v f}$ & e_dl_cpi_vfood & $\begin{array}{l}\text { Expected volatile food inflation (percent, QoQ } \\
\text { annualized) }\end{array}$ \\
\hline${ }^{e} \pi^{e t}$ & e_dl_cpi_et & $\begin{array}{l}\text { Expected energy \& transport inflation (percent, QoQ } \\
\text { annualized) }\end{array}$ \\
\hline$\hat{\pi}$ & infl_dev & Inflation deviation from the target (p.p.) \\
\hline $\bar{\pi}$ & pie_tar & Inflation target (percent) \\
\hline $\bar{\pi}^{v f}$ & pie_tar_vfood & Volatile food inflation target (percent) \\
\hline $\bar{\pi}^{e t}$ & pie_tar_et & Energy \& Transport inflation target (percent) \\
\hline$\pi^{\text {disc }}$ & dl_cpi_disc & Headline CPI Discrepancy \\
\hline$r p^{v f / c}$ & I_rp_vfood & V.Food/Core relative price $(100 * \log )$ \\
\hline$\overline{r p}^{v f / c}$ & I_rp_vfood_tnd & V.Food/Core relative price trend $(100 * \log )$ \\
\hline$\hat{r p p}^{v f / c}$ & I_rp_vfood_gap & V.Food/Core relative price gap (percent) \\
\hline$\Delta \overline{r p}^{v f / c}$ & dl_rp_vfood_tnd & $\begin{array}{l}\text { V.Food/Core relative price trend growth (percent, QoQ } \\
\text { annualized) }\end{array}$ \\
\hline$\Delta^{4} \overline{r p}^{v f / c}$ & d4l_rp_vfood_tnd & V.Food/Core relative price trend growth (percent, YoY) \\
\hline$r p^{e t / c}$ & I_rp_et & Energy\&Transport/Core relative price $(100 * \log )$ \\
\hline$\overline{r p}^{e t / c}$ & I_rp_et_tnd & Energy\&Transport/Core relative price trend $(100 * \log )$ \\
\hline$\hat{r p}^{e t / c}$ & I_rp_et_gap & Energy\&Transport/Core relative price gap (percent) \\
\hline$\Delta \overline{r p}^{e t / c}$ & dl_rp_et_tnd & $\begin{array}{l}\text { Energy\&Transport/Core relative price trend growth } \\
\text { (percent, QoQ annualized) }\end{array}$ \\
\hline$\Delta^{4} \overline{r p}^{e t / c}$ & d4l_rp_et_tnd & $\begin{array}{l}\text { Energy\&Transport/Core relative price trend growth } \\
\text { (percent, YoY) }\end{array}$ \\
\hline$\Delta s$ & dl_s & $\begin{array}{l}\text { Nominal depreciation of LKR per USD (percent, QoQ } \\
\text { annualized) }\end{array}$ \\
\hline$\Delta^{4} S$ & d4l_s & Nominal depreciation of LKR per USD (percent, YoY) \\
\hline$S$ & I_s & Nominal exchange rate LKR per USD $\left(100^{*} \log \right)$ \\
\hline$e_{S}$ & e_I_s & Expected nominal exchange rate $(100 * \log )$ \\
\hline$s^{p o l}$ & I_s_pol & FX smoothing policy exchange rate $\left(100^{*} \log \right)$ \\
\hline$s^{u i p}$ & I_s_uip & $\begin{array}{l}\text { Exchange rate consistent with IT interest rates } \\
(100 * \log )\end{array}$ \\
\hline$\Delta s^{p o l}$ & dl_s_pol & $\begin{array}{l}\text { Targeted exchange depreciation (percent, QoQ } \\
\text { annualized) }\end{array}$ \\
\hline$\Delta s^{u i p}$ & dl_s_uip & $\begin{array}{l}\text { Exchange rate depreciation consistent with IT interest } \\
\text { rates }(100 * \log )\end{array}$ \\
\hline$\Delta z$ & dl_z & RER depreciation (percent, QoQ annualized) \\
\hline
\end{tabular}




\begin{tabular}{|c|c|c|}
\hline Variable & Model name & Description \\
\hline$z$ & I_z & Real exchange rate $(100 * \log )$ \\
\hline$\hat{Z}$ & I_z_gap & Real exchange rate gap (percent) \\
\hline $\bar{Z}$ & I_z_tnd & Eq. real exchange rate $(100 * \log )$ \\
\hline$\Delta \bar{z}$ & dl_z_tnd & Eq. real depreciation (percent, QoQ annualized) \\
\hline$\rho$ & prem & Risk premium (percent p.a.) \\
\hline$\hat{y}^{\text {foreign }}$ & I_y_gap_f & Foreign output gap (\%) \\
\hline$r^{\text {foreign }}$ & $r_{-} f$ & Foreign real interest rate (percent p.a.) \\
\hline$i^{\text {foreign }}$ & $r n \_f$ & Fed Funds rate (percent p.a.) \\
\hline $\bar{r}^{\text {foreign }}$ & rr_tnd_f & Foreign equilibrium real interest rate (percent p.a.) \\
\hline$\pi^{\text {foreign }}$ & dl_cpi_f & Foreign CPI inflation (percent, QoQ annualized) \\
\hline$p^{\text {foreign }}$ & I_cpi_f & Foreign CPI $(100 * \log )$ \\
\hline$p^{o i l}$ & I_oil & Brent oil price $(100 * \log )$ \\
\hline$q^{o i l}$ & I_roil & Real oil price $(100 * \log )$ \\
\hline $\bar{q}^{\text {oil }}$ & I_roil_tnd & Real oil price trend $(100 * \log )$ \\
\hline$\hat{q}^{o i l}$ & I_roil_gap & World real oil price gap (percent) \\
\hline$\hat{q}^{\text {oil,et }}$ & I_roil_et_gap & Domestic real oil price gap (percent) \\
\hline$\Delta \bar{q}^{o i l}$ & dl_roil_tnd & Eq. real oil price growth (percent, QoQ annualized) \\
\hline$\Delta p^{o i l}$ & dl_oil & Growth of Brent oil price (percent, QoQ annualized) \\
\hline$\Delta p^{o i l, i m p, e t}$ & dl_oilimp_et & $\begin{array}{l}\text { Imported oil price inflation, energy\&transport } \\
\text { (percent, QoQ annualized) }\end{array}$ \\
\hline$p^{\text {food }}$ & I_food & FAO food price $(100 * \log )$ \\
\hline$q^{\text {food }}$ & I_rfood & Real food price $(100 * \log )$ \\
\hline $\bar{q}^{\text {food }}$ & I_rfood_tnd & Real food price trend $(100 * \log )$ \\
\hline$\hat{q}^{\text {food }}$ & I_rfood_gap & Real food price gap (percent) \\
\hline$\Delta \bar{q}^{\text {food }}$ & dl_rfood_tnd & Eq. real food price growth (percent, QoQ annualized) \\
\hline$\Delta p^{\text {food }}$ & dl_food & Growth of FAO food price (percent, QoQ annualized) \\
\hline$\Delta p^{\text {food,imp,c }}$ & dl_foodimp_core & $\begin{array}{l}\text { Imported food price inflation, core (percent, QoQ } \\
\text { annualized) }\end{array}$ \\
\hline
\end{tabular}


Table 5. Model Structural Shocks

\begin{tabular}{|c|c|c|c|}
\hline Shock & Model name & Description & StDev \\
\hline$\varepsilon^{\hat{y}}$ & shock_I_y_gap & Demand shock & 1.00 \\
\hline$\varepsilon^{i}$ & shock_rn & MP shock & 1.00 \\
\hline$\varepsilon^{\pi^{c}}$ & shock_dl_cpi_core & Core inflation shock & 1.50 \\
\hline$\varepsilon^{\pi^{v f}}$ & shock_dl_cpi_vfood & Volatile food inflation shock & 13.00 \\
\hline$\varepsilon^{\pi^{e t}}$ & shock_dl_cpi_et & Energy \& transport inflation shock & 15.00 \\
\hline$\varepsilon^{\pi^{d i s c}}$ & shock_dl_cpi_disc & CPI discrepancy shock & 0.70 \\
\hline$\varepsilon^{\Delta s}$ & shock_dl_s & UIP shock & 3.00 \\
\hline$\varepsilon^{\Delta \bar{y}}$ & shock_dl_y_tnd & Potential growth shock & 0.30 \\
\hline$\varepsilon^{\Delta \bar{z}}$ & shock_dl_z_tnd & Eq. RER shock & 0.30 \\
\hline$\varepsilon^{\rho}$ & shock_prem & Risk premium shock & 0.20 \\
\hline$\varepsilon^{\bar{\pi}}$ & shock_pie_tar & Inflation target shocks & 0.20 \\
\hline$\varepsilon^{\Delta s^{p o l}}$ & shock_dl_s_pol & Exchange rate policy shock & 3.00 \\
\hline$\varepsilon^{\Delta \overline{r p}^{v f / c}}$ & shock_dl_rp_vfood_tnd & Volatile food VS core relative price trend shock & 0.30 \\
\hline$\varepsilon^{\Delta \overline{r p}} \bar{c}^{e t / c}$ & shock_dl_rp_et_tnd & $\begin{array}{l}\text { Energy \& transport VS core relative price trend } \\
\text { shock }\end{array}$ & 0.50 \\
\hline$\varepsilon^{\hat{y}^{\text {foreign }}}$ & shock_I_y_gap_f & Foreign demand shock & 0.51 \\
\hline$\varepsilon^{i \text { foreign }}$ & shock_rn_f & Foreign MP shock & 0.37 \\
\hline$\varepsilon^{\bar{r}^{\text {foreign }}}$ & shock_rr_tnd_f & Foreign eq. real interest rate shock & 0.07 \\
\hline$\varepsilon^{\pi^{\text {foreign }}}$ & shock_dl_cpi_f & Foreign inflation shock & 2.27 \\
\hline$\varepsilon^{\hat{q}^{o i l}}$ & shock_I_roil_gap & Real oil price gap shock & 18.00 \\
\hline$\varepsilon^{\Delta \bar{q}^{o i l}}$ & shock_dl_roil_tnd & Eq. real oil price growth shock & 1.00 \\
\hline$\varepsilon^{\hat{q}^{f o o d}}$ & shock_I_rfood_gap & Real food price gap shock & 5.00 \\
\hline$\varepsilon^{\Delta \bar{q}^{\text {food }}}$ & shock_dl_rfood_tnd & Eq. real food price growth shock & 0.50 \\
\hline
\end{tabular}


Table 6. Model Parameters

\begin{tabular}{|c|c|c|c|}
\hline Parameter & Model name & Description & Value \\
\hline$\Delta \bar{z}_{S S}$ & ss_dl_z_tnd & Steady-state of RER depreciation & 2.000 \\
\hline $\bar{\pi}_{s S}$ & ss_pie_tar & Steady-state of headline inflation target & 4.879 \\
\hline$\rho_{s s}$ & ss_prem & Steady-state of the country risk premium & 5.000 \\
\hline$\Delta \bar{y}_{s S}$ & ss_dl_y_tnd & Steady-state of the potential output growth & 6.500 \\
\hline $\bar{r}_{S S}^{\text {foreign }}$ & ss_rr_tnd_f & Steady-state of the foreign real interest rate & 1.000 \\
\hline$\pi_{\text {ss }}^{\text {foreign }}$ & ss_dl_cpi_f & Steady-state of the foreign inflation & 2.000 \\
\hline$\Delta \overline{r p}_{s s}^{v f}$ & ss_dl_rp_vfood_tnd & $\begin{array}{l}\text { Steady-state of the change in volatile food relative } \\
\text { price }\end{array}$ & 0.000 \\
\hline$\Delta \overline{r p}_{s s}^{e t}$ & ss_dl_rp_et_tnd & $\begin{array}{l}\text { Steady-state of the change in energy and transport } \\
\text { relative price }\end{array}$ & 0.000 \\
\hline$a_{1}$ & c1_I_y_gap & Backward-lookingness in demand & 0.548 \\
\hline$a_{2}$ & c2_I_y_gap & Forward-lookingness in demand & 0.200 \\
\hline$a_{3}$ & c3_I_y_gap & Elasticity of demand on real interest rate & 0.035 \\
\hline$a_{4}$ & c4_I_y_gap & Elasticity of demand on foreign demand & 0.094 \\
\hline$a_{5}$ & c5_I_y_gap & Elasticity of demand on real exchange rate & 0.064 \\
\hline$a_{6}$ & c1_dl_y_tnd & Persistence of potential real GDP growth & 0.900 \\
\hline$a_{7}$ & c1_rn & $\begin{array}{l}\text { Interest rate smoothing in IT consistent monetary } \\
\text { policy rule }\end{array}$ & 0.813 \\
\hline$a_{8}$ & c2_rn & $\begin{array}{l}\text { Weight on inflation objective in in IT consistent } \\
\text { monetary policy rule }\end{array}$ & 0.774 \\
\hline$a_{9}$ & c3_rn & $\begin{array}{l}\text { Weight on output objective in in IT consistent } \\
\text { monetary policy rule }\end{array}$ & 0.099 \\
\hline$a_{10}$ & c1_dl_s_pol & $\begin{array}{l}\text { Weight on exchange rate smoothing in FX policy } \\
\text { rule }\end{array}$ & 0.500 \\
\hline$a_{11}$ & c2_dl_s_pol & $\begin{array}{l}\text { Weight on real exchange rate misalignment in FX } \\
\text { policy rule }\end{array}$ & 0.822 \\
\hline$a_{12}$ & w_rn_rule & $\begin{array}{l}\text { Relative importance of IT in decision maker } \\
\text { preferences }\end{array}$ & 0.807 \\
\hline$a_{13}$ & w_vfood & Weight of volatile food in CPI & 0.185 \\
\hline$a_{14}$ & w_core & Weight of energy and transport in CPI & 0.689 \\
\hline$a_{15}$ & c1_dl_cpi_core & Elasticity of core inflation on excess demand & 0.251 \\
\hline$a_{16}$ & c2_dl_cpi_core & Backward-lookingness in core inflation & 0.274 \\
\hline$a_{17}$ & c3_dl_cpi_core & $\begin{array}{l}\text { Elasticity of core inflation on imports as a part of } \\
\text { real marginal costs }\end{array}$ & 0.137 \\
\hline
\end{tabular}


Parameter Model name

$a_{18} \quad$ c4_dl_cpi_core

$a_{19} \quad$ c5_dl_cpi_core

$a_{20} \quad$ c1_dl_cpi_vfood

$a_{21} \quad$ c2_dl_cpi_vfood

$a_{22} \quad$ c1_dl_cpi_et

$a_{23} \quad$ c2_dl_cpi_et

$a_{24} \quad$ c3_dl_cpi_et

$a_{25} \quad$ c4_dl_cpi_et

$a_{26} \quad$ c1_dl_cpi_disc

$a_{27} \quad$ c1_dl_rp_vfood_tnd

$a_{28} \quad$ c1_dl_rp_et_tnd

$a_{29} \quad$ c1_pie_tar

$a_{30} \quad$ c1_dl_z_tnd

$a_{31} \quad$ c1_e_l_s

$a_{32} \quad$ c1_prem

$a_{33} \quad$ c1_I_y_gap_f

$a_{34}$ c1_rn_f

$a_{35} \quad$ c1_rr_tnd_f

$a_{36} \quad$ c1_dl_cpi_f

$a_{37} \quad$ ss_dl_roil_tnd

$a_{38} \quad$ c1_I_roil_gap

$a_{39} \quad$ c1_dl_roil_tnd

$a_{40} \quad$ ss_dl_rfood_tnd

$a_{41} \quad$ c1_I_rfood_gap

$a_{42} \quad$ c1_dl_rfood_tnd
Description

Value

Elasticity of core prices on energy and transport

0.043 prices

Elasticity of core inflation on imported food inflation

Persistence of volatile food inflation

Elasticity of volatile food inflation of relative price

1.290 gap

Persistence of energy and transport inflation

Elasticity of energy and transport inflation on imported oil inflation

Elasticity of energy and transport inflation on oil

0.166 price gap

Elasticity of volatile food inflation of relative price gap

Persistence of discrepancy in headline inflation identity

0.079

0.900

0.900 trend

Persistence of inflation target

1.000

Persistence of equilibrium real exchange rate

0.900 appreciation

Forward-lookingness in exchange rate

0.872

Persistence of country risk premium

Persistence of foreign output gap

Persistence of foreign nominal interest rate

0.500

Persistence of foreign equilibrium real interest rate

0.500

Persistence of foreign inflation

0.285

Long-run inflation of (real) oil prices

7.500

Persistence of gap in world oil prices

0.750

Persistence of equilibrium world oil price inflation

0.950

Long-run inflation of (real) food prices

7.000

Persistence of gap in world food prices

0.900

Persistence of equilibrium world food price

0.950 inflation 